\title{
Structural Biology of DNA Repair: Spatial Organisation of the Multicomponent Complexes of Nonhomologous End Joining
}

\author{
Takashi Ochi, Bancinyane Lynn Sibanda, Qian Wu, Dimitri Y. Chirgadze, \\ Victor M. Bolanos-Garcia, and Tom L. Blundell
}

Department of Biochemistry, University of Cambridge, Tennis Court Road, Cambridge CB2 1GA, UK

Correspondence should be addressed to Takashi Ochi, takashi@cryst.bioc.cam.ac.uk

Received 22 May 2010; Accepted 2 July 2010

Academic Editor: Ashis Basu

Copyright (C) 2010 Takashi Ochi et al. This is an open access article distributed under the Creative Commons Attribution License, which permits unrestricted use, distribution, and reproduction in any medium, provided the original work is properly cited.

\begin{abstract}
Nonhomologous end joining (NHEJ) plays a major role in double-strand break DNA repair, which involves a series of steps mediated by multiprotein complexes. A ring-shaped Ku70/Ku80 heterodimer forms first at broken DNA ends, DNA-dependent protein kinase catalytic subunit (DNA-PKcs) binds to mediate synapsis and nucleases process DNA overhangs. DNA ligase IV (LigIV) is recruited as a complex with XRCC4 for ligation, with XLF/Cernunnos, playing a role in enhancing activity of LigIV. We describe how a combination of methods-X-ray crystallography, electron microscopy and small angle X-ray scatteringcan give insights into the transient multicomponent complexes that mediate NHEJ. We first consider the organisation of DNA$\mathrm{PKcs} / \mathrm{Ku} 70 / \mathrm{Ku}$ 80/DNA complex (DNA-PK) and then discuss emerging evidence concerning LigIV/XRCC4/XLF/DNA and higherorder complexes. We conclude by discussing roles of multiprotein systems in maintaining high signal-to-noise and the value of structural studies in developing new therapies in oncology and elsewhere.
\end{abstract}

\section{Introduction}

Nonhomologous End Joining (NHEJ) and Homologous Recombination (HR) comprise the two major modes of DNA double-strand break (DSB) repair in human cells. Although HR is dominant in late S/G2 phases when a sister chromatid is available [1], NHEJ, which does not require a template [2], plays a major role in G1/early $S$ phase [1]. It is predicted that in humans about 50 endogenous DSBs per cell during each cell cycle may occur [3]. These are mainly generated by ionizing radiation, reactive oxygen species, and DNA replication across a nick [2]. Unrepaired DSBs can cause catastrophic gene loss during cell division, leading to chromosomal translocations, increased mutation rates, and carcinogenesis [4]. The NHEJ system is also responsible for programmed DSBs in $\mathrm{V}(\mathrm{D}) \mathrm{J}$ recombination [5] and class switch recombination [6] during development of immune diversity. NHEJ has an alternative end-joining pathway, which is mostly microhomology-mediated end joining [7] and is independent of NHEJ components [8]. Here NHEJ implies the main NHEJ pathway.
The NHEJ pathway comprises three major steps: synapsis, end processing and ligation [9]. Synapsis is carried out by DNA-dependent protein kinase (DNA-PK) consisting of Ku70, Ku80, DNA-PK catalytic subunit (DNAPKcs), and DNA. Ku70 and Ku80 form a ring-shaped heterodimer around the broken DNA ends and maintain them in proximity $[10,11]$. DNA-PKcs, a very large protein belonging to the phosphatidylinositol-3-OH kinase (PI3K)related kinase (PIKKs) family [12], is recruited through interaction with the C-terminus of $\mathrm{Ku} 80$ [13, 14], and causes the Ku70/80 heterodimer to move about one helical turn inward from the end [15] to make space for DNAPKcs to bind DNA. Two DNA-PK assemblies are probably required to hold the two DNA ends close together [16]. Activated DNA-PKcs phosphorylates itself and various proteins, including the other NHEJ components [17, 18]. Synapsis induces the autophosphorylation of DNA-PKcs and allows other NHEJ proteins access to DNA ends [19, 20].

The end processing involves nucleases such as Artemis [21], which is capable of cutting an array of DNA overhangs 
and is thought to be sufficient as a nuclease, although other nucleases in particular PNK, aprataxin (APTX), and PNK-APTX-like factor (PALF), a $3^{\prime}$ exonuclease, cannot be ruled out [22]. Artemis interacts with DNA-PKcs and opens DNA hairpins in the $\mathrm{V}(\mathrm{D}) \mathrm{J}$ recombination process [23]. Mutations in Artemis gene cause Radiosensitive Severe Combined Immunodeficiency (RS-SCID) [21]. Polymerases Pol $\mu$ and Pol $\lambda$ use their BRCT domains to bind to Ku/DNA complexes and terminal deoxynucleotidyl transferase (TdT) is exclusively expressed in initial lymphoid cells to engage in NHEJ of the $\mathrm{V}(\mathrm{D}) \mathrm{J}$ recombination process [24-26]. Furthermore, as recently shown $\mathrm{Ku}$ in its role as a lyase also participates in end processing cutting DNA $3^{\prime}$ at abasic sites, indicating that this protein, like its partner DNA-PKcs, has enzymatic properties and thus fulfils a number of roles in the NHEJ pathway [27].

The final ligation step of rejoining is mediated by DNA ligase IV (LigIV), which is associated with dimeric Xray cross-complementation group 4 (XRCC4) [28]. These proteins form a very stable complex, which is maintained at $2 \mathrm{M} \mathrm{NaCl}$ or $7 \mathrm{M}$ urea [29]. XRCC4 stimulates adenylation and ligase activity [30-32]. Knockouts of these genes in mice result in the late embryonic lethality in the p53-dependent manner [33-36] while mutations in lig4 gene result in LIG4 syndrome characterized by radiosensitivity, unusual facial features, microcephaly, developmental and growth delay, pancytopenia, and skin abnormality [37]. XRCC4Like Factor (XLF)/Cernunnos (XLF), mutations of which in humans cause Severe Combined Immunodeficiency, also interacts with XRCC4, and enhances the ligation by LigIV $[38,39]$.

Here we review what is known of the architectures of the transient multicomponent complexes that mediate Nonhomologous End Joining. Figure 1 is an attempt to construct an interaction diagram that summarises our current understanding of NHEJ protein interactions and phosphorylation by DNA-PKcs, indicating where structural information is available. Although the existence of DNAPK-the complex between DNA-PKcs, heterodimeric Ku and DNA - is clearly defined, as is the tight complex between XRCC4 and LigIV, the temporal and spatial organisation of higher-order complexes is unclear. Do subcomplexes exist that allow the Ku to get off the DNA before ligation, or is there one supercomplex in which DNA-PK, LigIV/XRCC4, and XLF coexist to achieve ligation? In this case, how does $\mathrm{Ku}$ leave when ends are ligated? In this paper, we first consider what is known about the structure of the huge single chain DNA-PKcs and how this might lead to a better understanding of the target for use in structure-guided drug discovery. We then discuss the organisation of DNA$\mathrm{PKcs} / \mathrm{Ku} 70 / \mathrm{Ku} 80 / \mathrm{DNA}$ complex (known as DNA-PK), in order to shed light on the initial events that take place in the NHEJ pathway. We discuss the emerging evidence concerning 3D structures of LigIV/XRCC4/XLF/DNA complexes, which should give clues about the binding and functional mechanism of LigIV/XRCC4 and XLF in NHEJ. Finally we consider the spatial arrangement of higher-order complexes in order to give a picture of the NHEJ repair system as a whole.

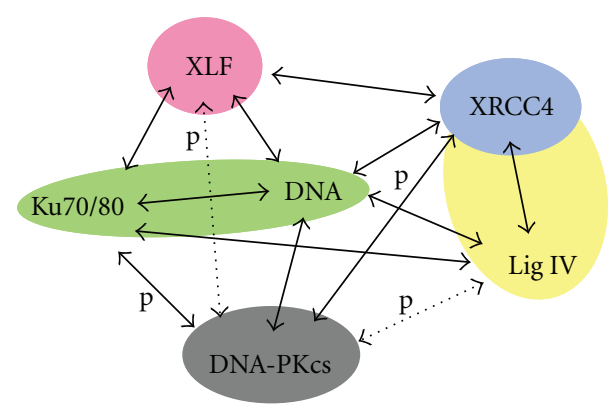

FIGURE 1: Schematic diagram of interactions of the NHEJ machinery. Colour-filled shapes indicate the proteins and complexes with known 3D structures. Solid arrows indicate confirmed whereas dashed arrows are plausible interactions. Phosphorylation events are indicated by letter " $p$ ".

\section{Structural Biology of Individual Components}

Considerable advances have been made in the structural biology of individual components and complexes of the NHEJ repair machinery, but further work is required to understand the spatial organisation of this complicated and dynamic process. Here we discuss what is known about each component before discussing the multiprotein complexes that mediate their functions in NHEJ.

2.1. Ku70/80. The double-stranded (ds) DNA end-binding activity of Ku70 and Ku80 requires their association to form a heterodimer [40]. The crystal structure of the Ku70/Ku80 heterodimer reveals a similar topology and domain organisation, comprising an amino-terminal $\alpha / \beta$ domain, a central $\beta$-barrel domain, and a helical C-terminal arm [10]. These proteins, when associated, form a pseudosymmetrical structure, in which residues that contribute to the dimer interface show a low level of sequence identity (approximately 15\%; Figure 2), favouring heterodimer formation over Ku70-Ku70 or Ku80-Ku80 homodimerisation.

The crystal structure of the Ku70/80 heterodimer in complex with one 55-nucleotide long Y-shaped DNA fragment shows that the Ku70/80 heterodimer adopts the shape of a ring that encircles duplex DNA (Figure 3). No large conformational changes occur on binding DNA to heterodimeric Ku except for the C-terminal domains of Ku70 and Ku80. Indeed, no contacts with DNA bases and only a few interactions with the sugar-phosphate backbone are made. The DNA duplex is embraced through the Ku70/80 preformed ring in such a way that one DNA face is relatively accessible to the solvent and therefore exposed to processing enzymes that remove damaged nucleotides and fill gaps prior to ligation. These features can provide structural support to broken DNA ends and bring the DNA helix into phase across the junction during end processing and ligation. Although Ku70/80 heterodimer shows low affinity for circularized DNA [43] and does not bind any DNA substrates shorter than $14 \mathrm{bp}$, it does bind dsDNA fragments of similar length and structure in a DNA sequence-independent fashion and irrespective of whether the DNA ends are blunt, with hairpin loops, or $5^{\prime}$ or $3^{\prime}$ overhangs. 

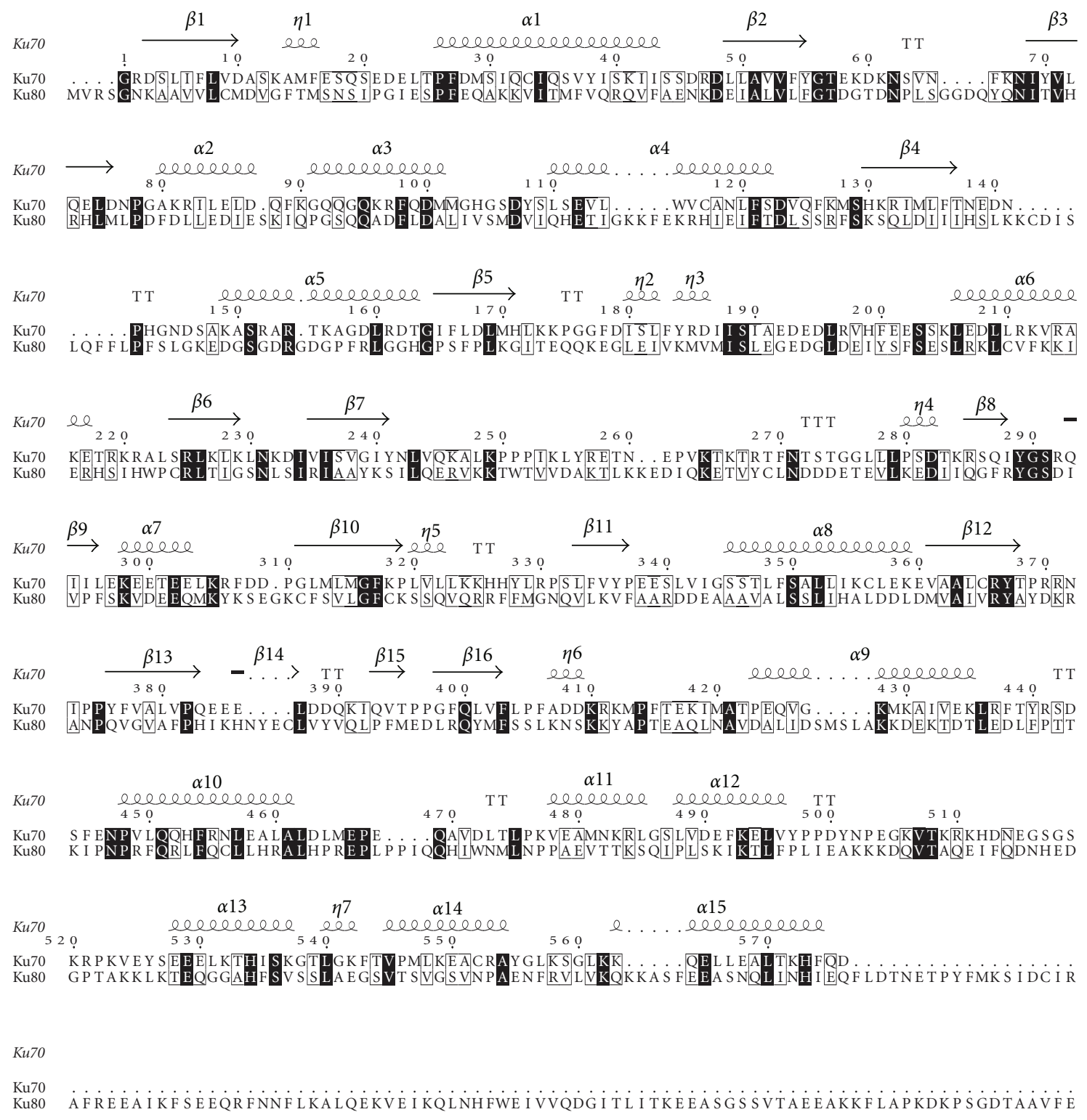

Figure 2: Ku70 and Ku80 aligned sequences on the basis of their structures. They show a similar domain organisation despite the low sequence identity. The alignment was created with ClustalW2 [41] and visualized with ESPript [42]. Many residues are conserved (black box) or semiconserved/similar (gray box).

2.2. DNA-PKcs. The structure of DNA-PKcs has proved quite elusive. Some beautiful work performed using cryoelectron microscopy single particle reconstruction of DNAPKcs [44-47] has given a good impression of the overall structure (see Figure 4(a)). This has now been complemented by work in our laboratory. We have shown that DNA-PKcs crystals can be grown and diffract to about $8.5 \AA$ resolution but the diffraction is better for the complexes with C-terminal fragments of Ku80, presumably due to a stabilization of the DNA-PKcs in the complex leading to better ordering of the crystal packing. We have recently used multiwavelength anomalous dispersion with the $\mathrm{Ta}_{6} \mathrm{Br}_{12}{ }^{2+}$ heavy-metal cluster [48] to solve the structure of DNAPKcs in complex with C-terminal domain of Ku80 at $6.6 \AA$ resolution (Figure 4(b)).

Much of the DNA-PKcs polypeptide chain is constructed from HEAT repeat units (Figure 5) to form several separate domains. The DNA-PKcs tertiary structure measures $160 \AA$ 


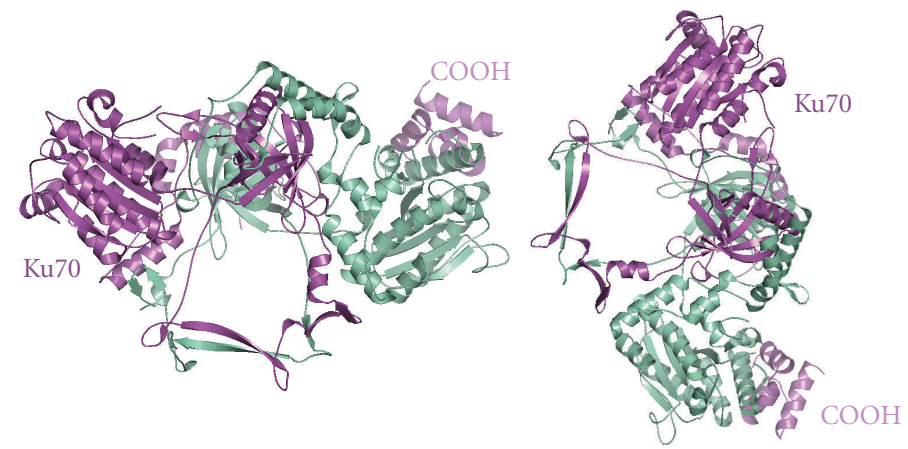

(a)
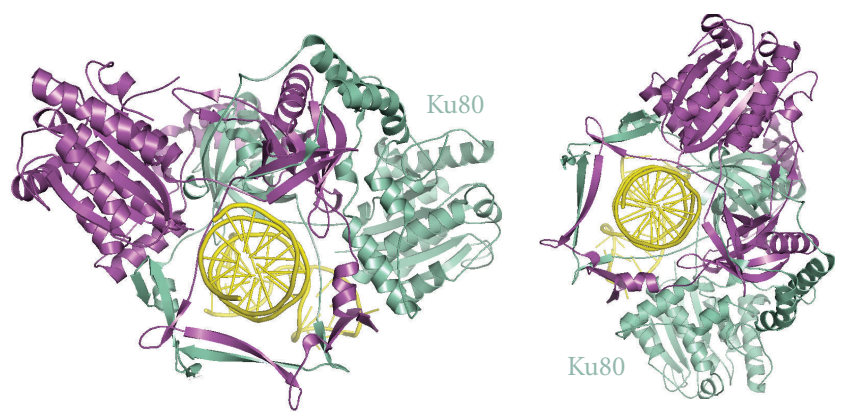

(b)

Figure 3: Heterodimerisation of Ku70/80 defines a ring shape that binds DNA. Crystal structures of Ku70/80 heterodimer in the absence of DNA (a) and in DNA-bound form (b). Adapted from [10].

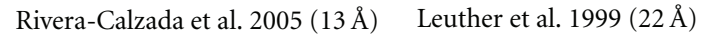

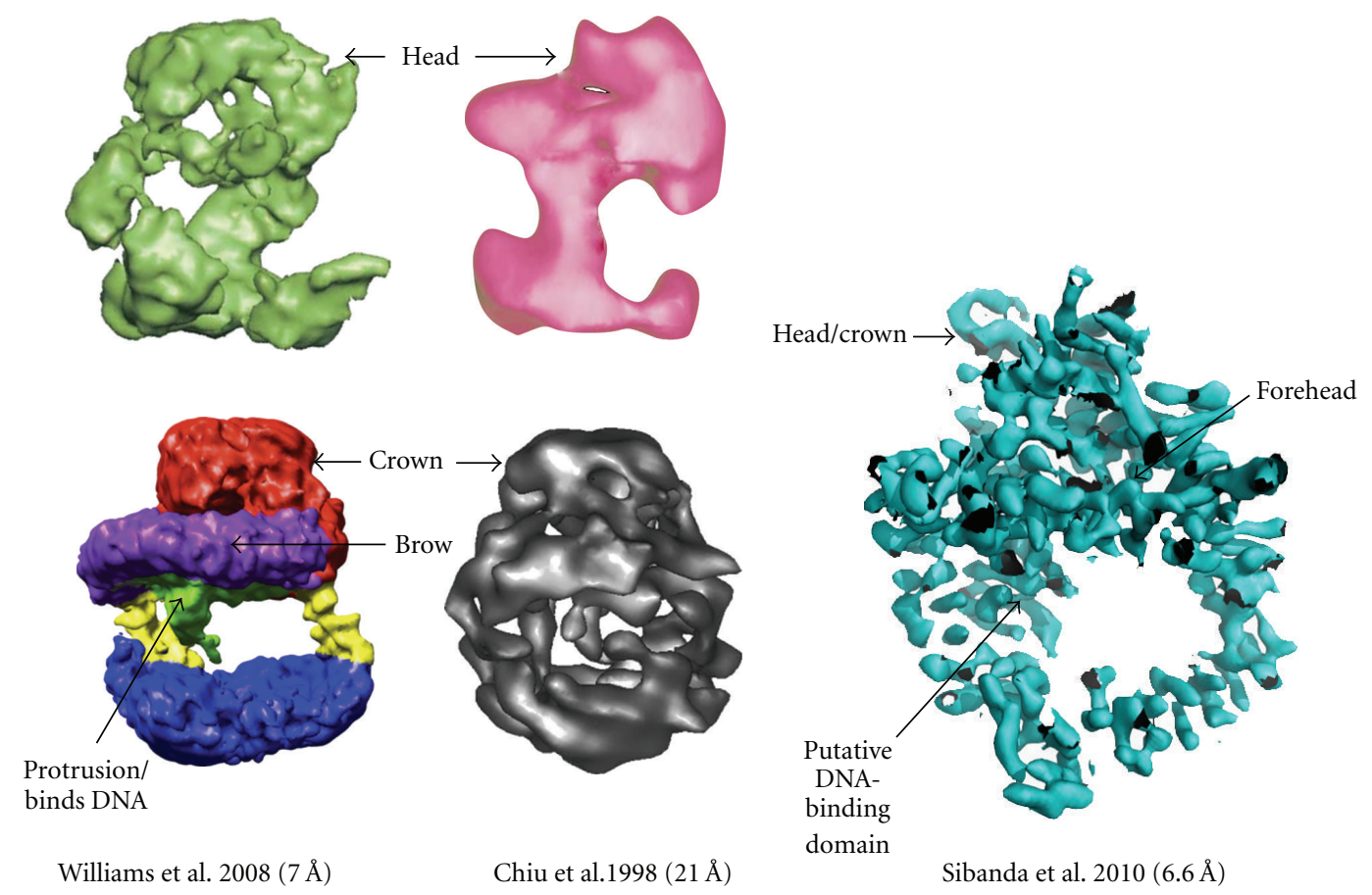

(a) Cryo-electron Microscopy

(b) X-ray Crystallography

Figure 4: Equivalent views of DNA-PKcs as defined by (a) Cryo-electron microscopy and (b) X-ray protein crystallography. References to the publications and resolutions of the models are given above. Colour coding of these EM structures are as given in their respective publications [44-47]. The X-ray crystallographic experimental electron density map is as defined by Sibanda et al. [48]. 


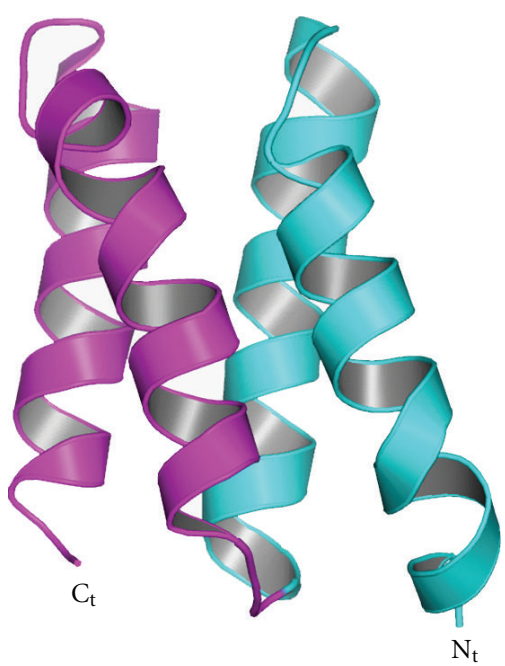

Figure 5: An example of HEAT-repeat motifs. Two consecutive $\alpha$ helical hairpins are shown.

high and $120 \AA$ across as viewed in Figure 6(a). From the $\mathrm{N}$-terminus, HEAT-repeat motifs comprising about $66 \alpha$ helices fold into a hollow circular structure, which when viewed from the side resembles a cradle (Figure 6(b)). The chain changes direction before the circle is complete, thus leaving a gap (Figure 6(a)). Within this circular structure the regularity of the HEAT repeats breaks down at certain points, as indicated in Figure 6(a) with blue arrows. These points of irregularity may play a part in conformational changes that have been implicated in the function of this molecule [16]. It is possible that these conformational changes could have a bearing on the size of the gap (Figure 6(a)), which may have a role in the release of DNA-PKcs from DNA ends when NHEJ is complete. The ring structure most likely acts as a platform for proteins that engage in repair of broken DNA and together with Ku holds in place the DNA while it is being repaired.

In the second part of the structure the polypeptide chain exploits HEAT repeats to fold into a small, globular, putative DNA-binding domain within the circular structure. It is known that DNA-PKcs binds both double-stranded and single-stranded DNA. Williams et al. (2008) have proposed that "the protrusion" in their cryo-EM structure binds DNA [47], and this protrusion is equivalent to the small globular domain located within the circular region of the crystal structure. This remains the best candidate for both singleand double-stranded DNA recognition, but further work on DNA-PK (DNA-PKcs, Ku, DNA complex) crystals at a higher resolution structure of DNA-PKcs will be needed to confirm this. Thirdly, the C-terminal region folds into the Head/Crown that is perched right at the top of the cradle shaped circular structure and extends further back. This part contains the FAT, kinase domain, FATC, and various parts where other proteins, as indicated by biochemical studies, may bind to form complexes with DNA-PKcs (Figure 7).

The core of the kinase structure from $\mathrm{PI}(3) \mathrm{K} \gamma$, one of the family members, was superposed onto this Head/Crown region resulting in a plausible fit to the $\mathrm{N}$-lobe $\beta$-strands and the C-lobe $\alpha$-helices (Figure 8 ). In this location the kinase is exposed and easily accessible to substrates (Figure 8). From the location of the kinase domain the positions of the FAT and FATC regions can be inferred (Figure 7) as the kinase domain likely "snuggles" in between these two regions [62].

The size of the monomer of DNA-PKcs is predicted by small angle X-ray scattering (SAXS) to be about $155 \AA$ [63], broadly in agreement with that of the crystallographic structure. DNA-PKcs dimerizes without DNA in a concentration-dependent manner. SAXS data indicate a large conformational change between autophosphorylated and unphosphorylated DNA-PKcs; the dimension and radius of gyration of phosphorylated DNA-PKcs increased 25 and $2 \AA$, respectively, compared to mock DNA-PKcs. Also, shape reconstruction of phosphorylated DNA-PKcs shows a wider cleft between head and palm domains than in the unphosphorylated enzyme.

2.3. DNA Ligase IV. Human LigIV has also proved difficult to study in isolation due to instability and flexibility but it is stabilised by interaction with XRCC4 [28]. In human, LigIV is one of three ATP-dependent DNA ligases, I, III, and IV, and plays a central role in eukaryotic NHEJ. LigIV can be divided into the catalytic and interaction regions. There are excellent reviews of the comparison of structures of DNA and RNA ligases, and RNA capping enzymes elsewhere [64-67].

LigIV belongs to the nucleotidyltransferase superfamily and carries out a three-step nucleotidyl transfer reaction: the formation of covalent enzyme-nucleotide monophosphate (NMP) intermediate (step 1), the transformation of the NMP to a $5^{\prime}$-phosphate of polynucleotide (step 2), and the joining of the $5^{\prime}$-phosphate with $3^{\prime}$-hydroxyl to seal two polynucleotides (step 3) [68]. These enzymes have four common motifs (I, III, IV, V) and in addition two more motifs (III $\alpha$ and VI), which are conserved among the cellular and ASF virus capping enzymes and eukaryotic ATP-dependent DNA ligases [69]. A recently found motif, $\mathrm{Va}$, is well conserved among human DNA ligases [70]. The motif I $\mathrm{KX}(\mathrm{D} / \mathrm{N}) \mathrm{G}$ has the catalytic lysine which forms the NMP-covalent intermediate. Motifs I-V are located in the nucleotidyltransferase domain (NTase) (Figure 9), the core of which comprises three mainly antiparallel $\beta$-sheets flanked by six $\alpha$-helices [64]. Motifs Va and VI belong to the oligonucleotide/oligosaccharide-binding domain (OBD) (Figure 9), which has the five stranded Greek-key $\beta$-barrel capped by an $\alpha$-helix $[64,71]$. NTase and OBD are conserved among capping enzymes and DNA ligases [64]. Most LigIV syndrome mutations are found in the NTase and OBD [72] (Figure 9).

Many enzymes in the nucleotidyltrasferase superfamily have extra domains in addition to conserved catalytic core domains. N-terminal to the NTase, for instance, the human DNA ligases have DNA-binding domain (DBD), the threedimensional structure of which was first uncovered by Pascal et al. (2004) with the catalytic domains of human DNA ligase I (LigI) complexed with an unligatable, nicked DNA fragment [73]. This domain is also found in archaeal DNA 




(a)

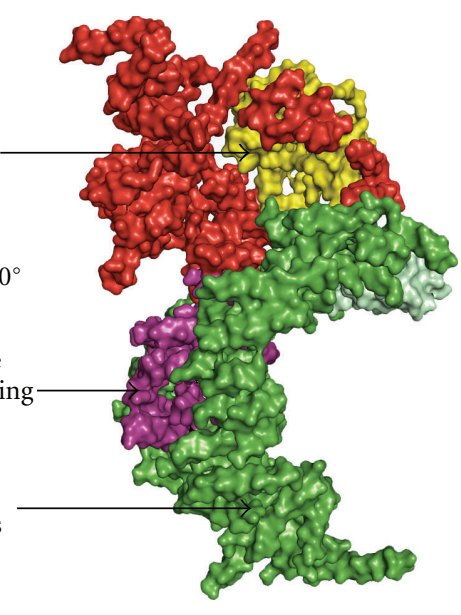

(b)

FIgURE 6: Crystal structure of DNA-PKcs. Molecular surface of the DNA-PKcs structure showing (a) front and (b) side views. Also shown in (a), is the overall size of DNA-PKcs with the potential flexible sites indicated in blue arrows. The molecule is colour coded as follows: the ring structure that is predominantly HEAT repeats is green; the forehead that is part of the ring structure is light green; the putative DNA binding domain is magenta; the larger C-terminal part that includes the FAT and FATC domains is red, and the kinase domain is yellow.

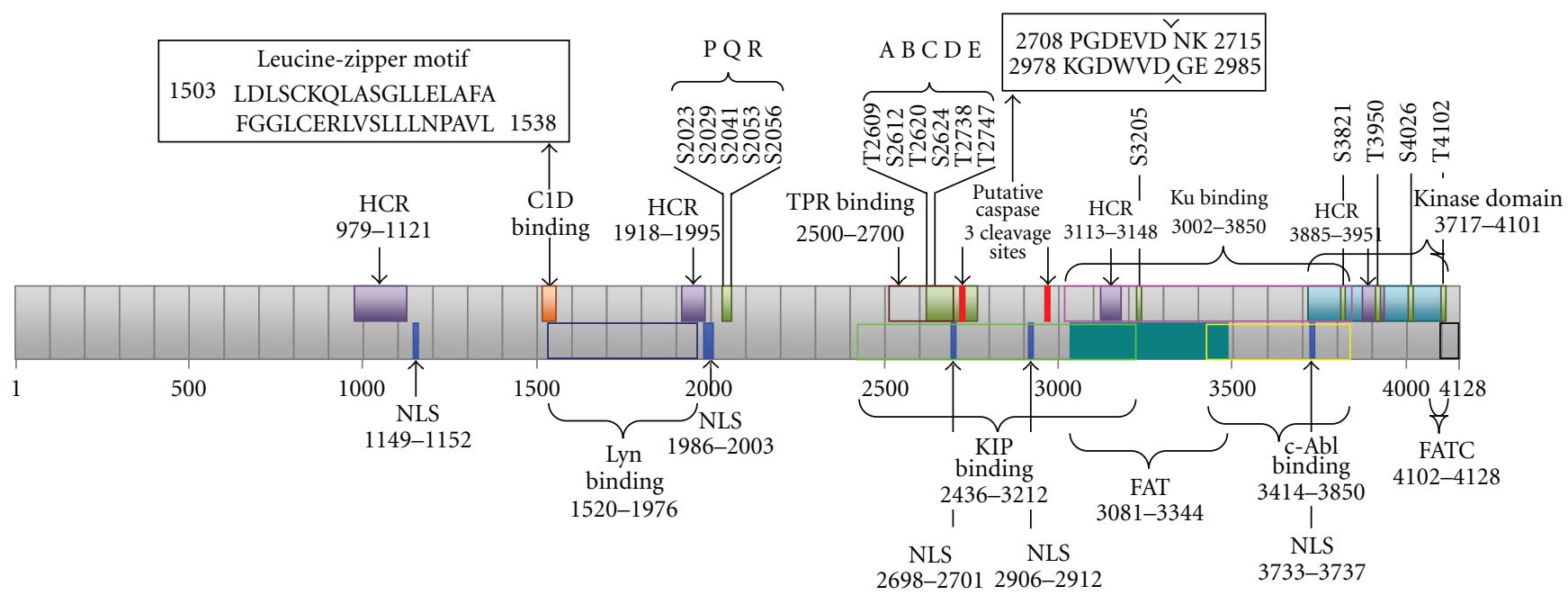

FIGURE 7: Schematic diagram of DNA-PKcs sequence-function implications. Shown are four highly conserved regions (HCR) [49]; Kinase, FAT, and FATC domains; putative sites for nuclear localization signals (NLSs) [49]; Autophosphorylation sites PQR [50], ABCDE [19], S3205 [51], S3821, S4026, T4102 [52], and T3950 [53]; cleavage sites for apoptotic protease caspase-3 [49, 54-56]; binding sites for Lyn tyrosine kinase [57], C1D protein that interacts at the leucine-zipper motif of DNA-PKcs [58], protein phosphatase-5 (PP5) that binds, using its tetratricopeptide repeat (TPR), to dephosphorylate DNA-PKcs at S2056 and T2609 [59], Ku70/80 that binds to present the damaged DNA double strand ends to DNA-PKcs [60], the kinase interacting protein (KIP) [61], and c-Abl that binds using its $\mathrm{SH}_{3}$ a binding that is triggered by DNA damage [60].

ligases [74-76] and possibly other eukaryotic, Poxvirus, and archaeal DNA ligases [77]. Pascal et al. (2004) showed that DBD is essential for LigI to bind DNA and to carry out ligation of DNA nicks [73]. However, this does not seem to be the case for DNA ligase III [78], although most DNA-binding affinity of LigIV seems to come from its DBD (T Ochi and TL Blundell, unpublished results). These results suggest that
DBD of each human DNA ligase has different DNA-binding properties, although they are likely to have similar structures [79]. Two LigIV syndrome mutations are severe only when they are combined with $\mathrm{R} 278 \mathrm{H}$, and they seem to have little impact on LigIV activity [37]. On the basis of structural similarities of the catalytic regions of LigI and LigIV, they are likely to bind DNA in a similar manner. 


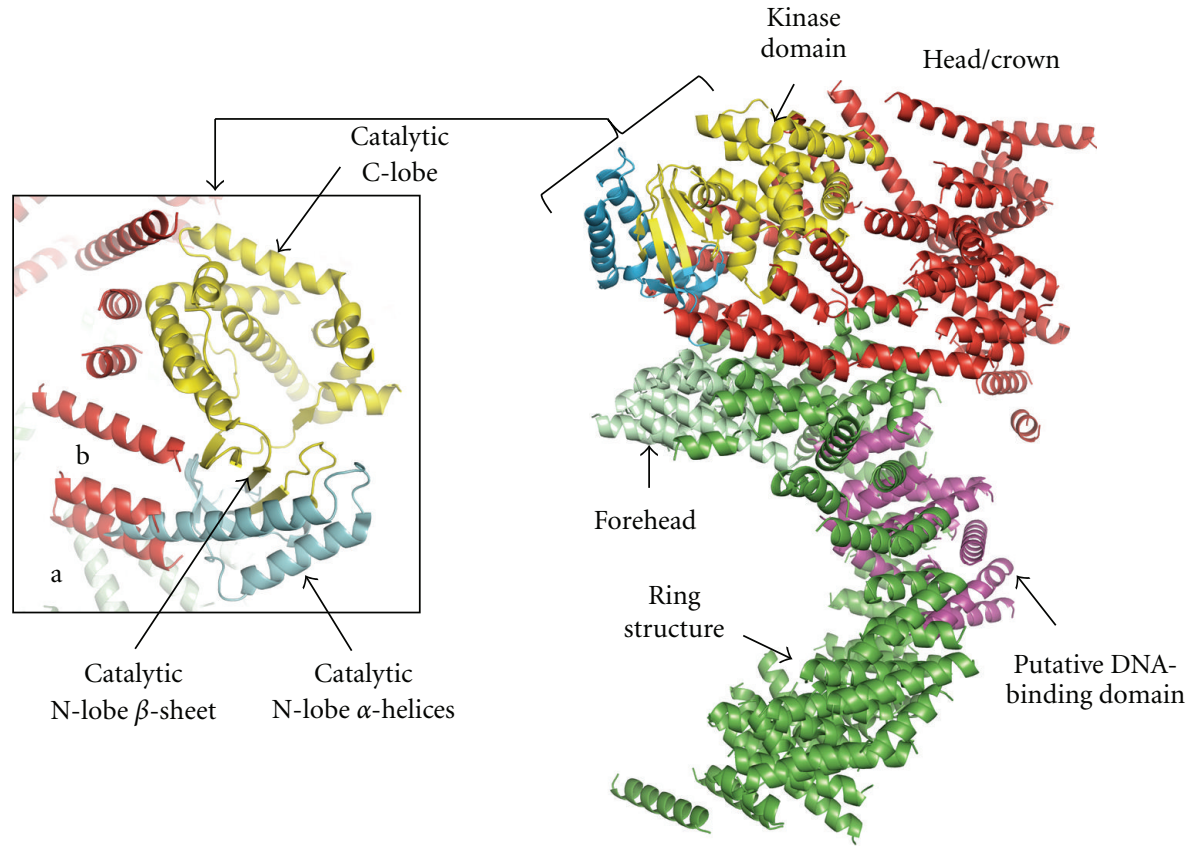

Figure 8: DNA-PKcs kinase domain. The figure shows a cartoon of the overall structure of DNA-PKcs depicting the position of the kinase domain. The colour coding is as shown in Figure 6. The modelling of DNA-PKcs catalytic domain was based on the crystal structure of one of its family members, the PI(3)K $\gamma$ kinase (PDB code: 1E8X). Also shown is a closeup of DNA-PKcs catalytic domain. Helices of DNA-PKcs labelled (a) and (b) could be occupied by helices from the N-lobe of $\mathrm{PI}(3) \mathrm{K} \gamma$. The N-lobe helices displayed in light blue were omitted from the final structure of DNA-PKcs due to unclear electron density in this region.

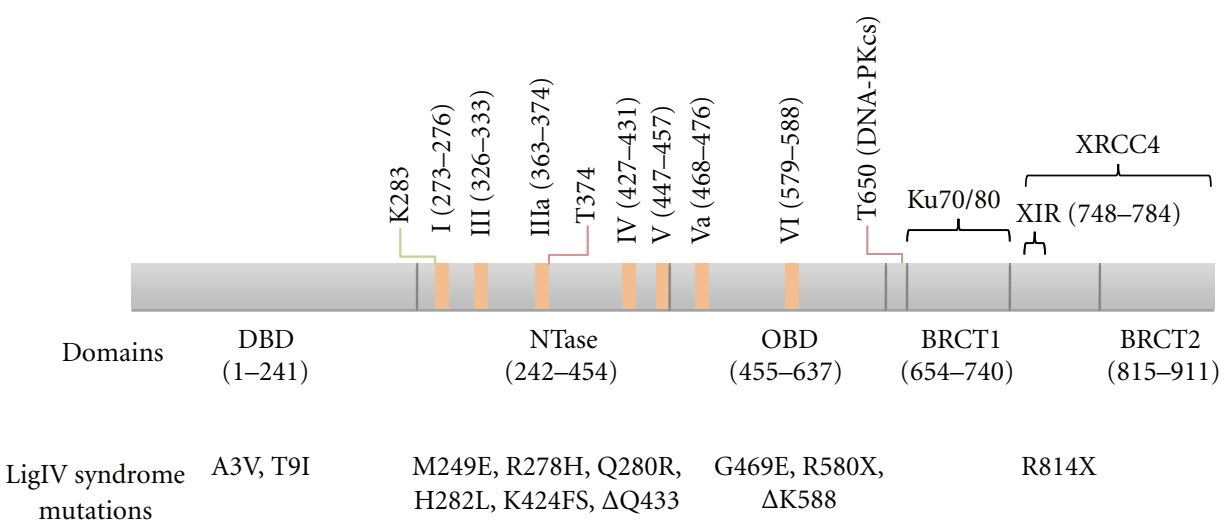

Figure 9: Schematic diagram of human DNA ligase IV. Domain boundaries shown in the figure are based on the crystallographic structure of human DNA ligase I [73] and BRCT domains of LigIV [94]. Conserved motifs (I, III, IIIa, IV, V, Va, and VI) are shown in orange rectangles $[69,70]$. The conserved catalytic lysine is indicated in green line. Reported phosphorylation sites are indicated by red lines [81, 99]. LigIV syndrome mutations are shown under domains $[72,100]$. Ku and XRCC4 interaction regions are indicated with black brackets [29, 84, 94].

In addition to the catalytic region, human DNA ligases have extra domains [79]. LigIV has a tandem BRCT domain with a linker predicted to be mostly disordered. This linker seems to be important for the catalytic activity of LigIV [80] and has a phosphorylation site at T650 by DNAPKcs, the phosphorylation of which stabilizes LigIV [81]. The BRCT domain, which typically has four parallel $\beta$ strands surrounded by three $\alpha$-helices [82], is common in cell cycle checkpoint proteins that respond to DNA damage [83]. LigIV interacts with XRCC4 mainly through the linker between the two BRCT [80]. As noted above, in addition to the interaction with XRCC4, the first BRCT domain (BRCT1) has been shown to interact with Ku70/80 [84].

Structures of tandem BRCT domains of human BRCA1 and MDC1, yeast Crb2, Nbs1, and Brc1, have been solved with different phosphopeptides. Four key residues that form the phospho-serine binding pocket - the $(\mathrm{S} / \mathrm{T}) \mathrm{G}$ motif at the end of the first $\beta$-strand $(\beta 1)$ and the $(\mathrm{S} / \mathrm{T}) \mathrm{XK}$ motif at the beginning of the second helix $(\alpha 2)$ [85-93] have been identified; the residues are conserved in the tandem 


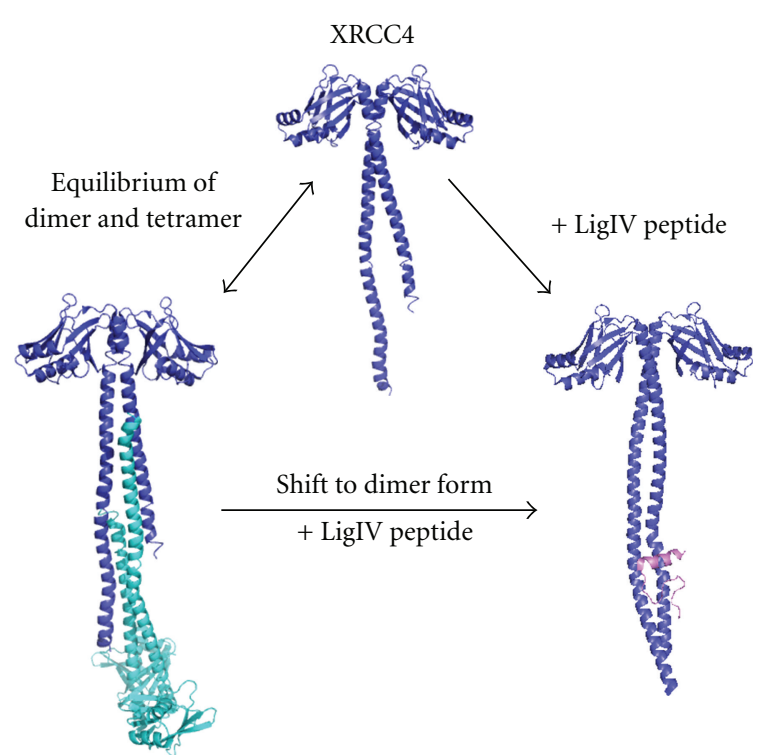

FIGURE 10: XRCC4 dimer, tetramer, and binding with DNA ligase IV peptide. The equilibrium is shifted to dimer when DNA ligase IV peptide binds to XRCC4.

BRCT domain of LigIV except that the second motif is replaced by NXR. Thus BRCT1 might bind to phosphoserines [94], although the interactions with the two proximal BRCT domains found in BRCA1, MDC1, Crb2, Nbs1, and Brcl are unlikely to occur in LigIV as the tandem BRCT domains are probably positioned apart [94, 95]. Indeed, in vitro phosphopeptide binding experiments showed that BRCT domains of LigIV bound phosphopeptides [96, 97]. However, the precise sequence of a phosphopeptide that binds to the BRCT domains has not yet been determined.

Since the tandem BRCT domains have a common globular arrangement of the BRCT domains, LigIV domains may interact when LigIV is in the free form. The main dimerization interface of the tandem BRCT domain is $\alpha 2$ in BRCT1, and the first and third helices $\alpha^{\prime} 1$ and $\alpha^{\prime} 3$ in the second BRCT domain (BRCT2) [98]. Interestingly, the interaction surface of those BRCT domains and XRCC4 is similar to that of other tandem BRCT domains (as discussed below). It is possible that a BRCT domain from another protein interacts with $\alpha 2$ of BRCT1, which is exposed to the solvent. Thus, although the tandem BRCT domains of LigIV have a long linker, they have features in common with other tandem BRCT domains.

2.4. XRCC4. In solution, XRCC4 exists as a salt-dependent equilibrium of dimers and tetramers [102] see Figure 10. Tail-to-tail tetramerisation was observed in XRCC4 protein crystals [103]. Binding of LigIV with the XRCC4 C-terminal $\langle\alpha$-helical coiled-coil stabilizes the XRCC4 dimer formation. The binding region between XRCC4 and LigIV overlaps with the XRCC4 tetramerisation region, which may explain why LigIV functions to shift XRCC4 to dimer form in solution [102]. Whether tetrameric XRCC4 has a function during NHEJ repair pathway is still not known.
The protein sequence of XRCC4 after residue 213 is not included in XRCC4 crystal structures due to the expected highly disordered and flexible structure of XRCC4 Cterminal domain [103]. However, EM studies have revealed that mouse XRCC4 C-terminal structure is a globular domain [104]. This domain includes putative nuclear localization sequences [105]. These authors also suggested that a cluster of acidic amino acids $229-238$ is important for the auto-transcription activity. Furthermore, the XRCC4 Cterminal domain is the target for NHEJ regulatory proteins. DNA-PKcs phosphorylates XRCC4 and regulates its binding with DNA [31]. Residues S260 and S318 in the XRCC4 Cterminal region were identified to be the main phosphorylation sites by DNA-PKcs [106]. XRCC4 is also phosphorylated by $\mathrm{CK} 2$, residue $\mathrm{T} 233$ and the phosphorylation by $\mathrm{CK} 2$ recruits PNK, which is likely to participate in NHEJ [107]. Indeed the structure of the ForkHead-Associated (FHA) Domain of PNK with a XRCC4-derived phosphopeptide has been solved [108]. XRCC4 residue K210 was also reported to be important for small ubiquitin-like modifier (SUMO) modification, which regulates XRCC4 cellular localization [109]. The XRCC4 C-terminal region, together with the Nterminal region (residues 1-28) and central region (residues 168-200), may facilitate cooperative DNA binding [31]. Thus, definition of the structure of the C-terminal region structure will contribute to understanding how XRCC4 binds to LigIV and DNA in order to carry out its function.

2.5. XLF. XLF was identified through a cDNA functional complementation cloning study of patient $2 \mathrm{BN}$ following discovery of a group of NHEJ deficiency patients (2BN) $[38,110]$. It was also independently identified through yeast two-hybrid screening for XRCC4 interactors [39]. XLF is evolutionarily conserved throughout a wide range of eukaryotes such as vertebrates, insects, and even in filamentous fungi [111]. Full-length human XLF contains 299 residues. At its extreme C-terminus, a small conserved basic cluster constitutes the nuclear localization sequence. Using immunofluorescence staining, XLF was observed localizing in nucleus of human cells [39].

The crystal structure of XLF with a C-terminal truncation, solved independently at $2.3 \AA$ resolution by Andres et al. [112] and in our laboratory [101], exists as a homodimer containing a globular $\mathrm{N}$-terminal head domain and extended coiled-coil helical tail, which is folded back around the coiled-coil (Figure 11). The N-terminal head domain starts with a single helix $\alpha 1$, which is followed by a seven-stranded antiparallel $\beta$ structure sandwiching a helix-turn-helix motif between $\beta 4$ and $\beta 5$. The tail structure contains three helices $\alpha 4, \alpha 5$, and $\alpha 6$. While $\alpha 4$ extends away from $\mathrm{N}$-terminal head domain around $60 \AA, \alpha 5$ and $\alpha 6$ fold back and make contact with the head domain. The $\alpha 4$ helices from the two protomers interact as a coiled-coil structure burying highly conserved and hydrophobic residues at the interface. This dimerization of XLF is further enhanced through the folding back of the $\alpha 5$ and $\alpha 6$ helices to encircle the $\alpha 4$ helices of the other protomer to form a clamp, leading to burying of a surface area of $\sim 6500 \AA^{2}$. Gel filtration, protein crosslinking and analytical ultracentrifugation are also consistent with 



Figure 11: Crystal structure of XLF/Cernunnos. Ribbon diagram of the XLF/Cernunnos dimer. One protomer is rainbow colour going from $\mathrm{N}$-terminus (blue) to C-terminus (red). Adapted from Li et al. [101].

a stable homodimer form of XLF in solution [101]. XLF was found to have concentration-dependent higher-order complex formation during gel filtration experiments [112]. The homodimer of XLF, however, is the smallest stable functional unit.

Due to the predicted disordered structure for the XLF Cterminal region after residue 245 , around 70 residues were removed from the XLF C-terminus in the crystal structure analyses $[101,112]$. The approximate location of the XLF Cterminal region, however, can be predicted to be near the $\mathrm{N}$-terminal head domain region according to the helix $\alpha 6$ direction.

Although XLF and XRCC4 have similar architectures, large structural differences from head to tail occur between these two proteins. For the head domain, both proteins contain the same seven-stranded antiparallel $\beta$-structure sandwiching a helix-turn-helix motif, but XLF contains an extra helix at the $\mathrm{N}$-terminus. As we have seen, the tail structure of XLF contains distinct helices folding back, while the extended coiled-coil tail structure of XRCC4 contains the LigIV binding region near the C-terminus. The differences in sequence and structure between XLF and XRCC4 tails explain why LigIV does not bind to XLF in the same way as XRCC4.

The functions and mechanisms of action of XLF in NHEJ are still not fully understood. XLF not only stabilizes LigIV/XRCC4 at broken DNA ends, but also enhances the LigIV/XRCC4 end-joining process. XLF has also been found to be essential for repairing mismatched $3^{\prime}$ overhangs and the gap-filling process together with DNA polymerase pol $\lambda$ and pol $\mu[113,114]$. Understanding how XLF functions in NHEJ through studying its interaction with other NHEJ proteins structurally will help unravel the exact role of XLF. It will contribute towards our current understanding of DNA repair in NHEJ and may also potentially lead to future therapeutic application for NHEJ defects patients.

\section{Structural Biology of Complexes}

3.1. DNA-PKcs/Ku70/Ku80/DNA Ternary Complex (DNA$P K)$. The crystal structure of the Ku70/80 heterodimer does not include the C-terminal DNA-PKcs interaction domain of Ku80 (Ku80CTD), which is dispensable for the binding of Ku70/80 to DNA but is required for DNA-PK recruitment to the sites of damaged DNA $[13,14]$. Nuclear magnetic resonance analysis of $19 \mathrm{kDa}$ Ku80CTD (residues 545-732) defines an $\alpha$-helical structure $[115,116]$. Further structural studies of full-length Ku70/80 with and without DNA have been conducted using single-particle electron microscopy (EM) [117] and SAXS combined with live cell imaging [63]. The position of Ku80CTD was proposed to be under the $\alpha / \beta$ domain of Ku70 by EM, but the domain was found to be flexible in the SAXS study. Molecular dynamic simulations of Ku80CTD produced an ensemble of conformations, supporting the idea of Ku80CTD being a region of high flexibility [63]. Taken together, the studies show that association of Ku70 and Ku80 to form a heterodimer is required for binding dsDNA ends, that Ku-dependent DNA binding drives the recruitment of DNA-PKcs and that the latter interaction involves the helical domain located at the C-terminus of Ku80. Although Ku80CTD was included in the crystal structure of DNA-PKcs, its position could not be unequivocally defined, presumably due to the dominance of similar alpha helical structures in the DNA-PKcs itself [48].

Insights into the DNA-PKcs/Ku70/Ku80 holoenzyme structures and possible synaptic complexes have been obtained using cryo-electron microscopy and SAXS. Boskovic et al. (2003) used electron microscopy at low resolution $(\sim 30 \AA)$ to demonstrate large conformational changes in human DNA-PKcs when double-stranded DNA binds, and suggested that this may correlate with the activation of the kinase [118]. Subsequently, Spagnolo et al. (2006) have used single-particle electron microscopy at 


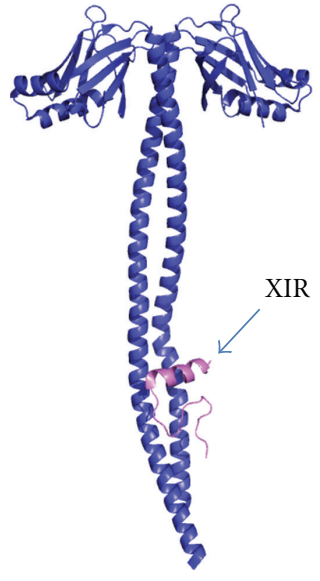

(a)

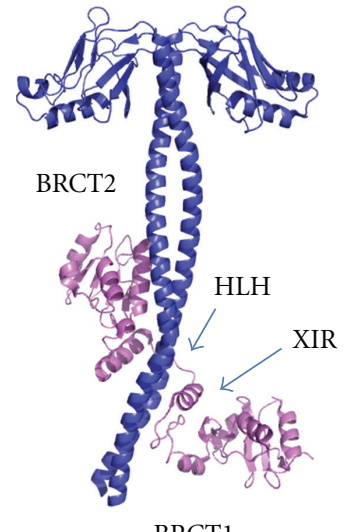

BRCT1

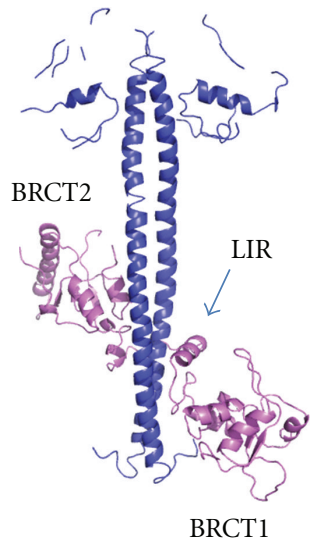

(c)

FIGURE 12: Crystal structures of LigIV/XRCC4 and Lif1p-Lig4p. Conserved XRCC4 or Lif1 interaction region of LigIV (XIR) or Lig4p (LIR) are indicated with blue arrows. (a) XRCC4(residues 1-213)(blue) and XIR (violet) (PDB code: 1IK9). (b) XRCC(residues 1-203)(blue) and BRCT domains of LigIV(residues 654-911)(violet) (PDB code: 3II6) (c) Liflp(residues 1-246)(blue) and BRCT domains of Lig4p(residues 680-944)(violet).

$\sim 25 \AA$ resolution to study human DNA-PKcs/Ku70/Ku80 holoenzyme assembled on DNA [16]. They again found evidence for conformational changes on binding of $\mathrm{Ku}$ and DNA to DNA-PKcs. They identified dimeric particles comprising two DNA-PKcs/Ku70/Ku80 holoenzymes, which they consider are likely to be synaptic complexes, maintaining broken ends and providing a platform for other components required for end processing and ligation. A SAXS study of DNA-PK revealed that it had two different modes of dimerization as was observed previously with DNA-PKcs [63]. Depending on the presence of either $40 \mathrm{bp}$ hairpin DNA or $40 \mathrm{bp}$ Y-shaped DNA, DNA-PK formed the head-to-head or palm-to-palm dimer. Very recently Perry et al. (2010) have taken study of the DNA$\mathrm{PKcs} / \mathrm{Ku} 70 / \mathrm{Ku} 80$ holoenzyme further by analyzing their earlier SAXS studies in the light of the crystal structure of DNA-PKcs [119]. They have impressively demonstrated that DNA-PK phosphorylation causes a large conformational change, sufficient to open the gap in the ring and provide access to or release from DNA. Ku80CTD has been shown to be flexible and to extend in solution to the benefit of recruitment of DNA-PKcs. It is possible that Ku80 interacts with DNA-PKcs on both sides of BSB [63].

3.2. DNA Ligase IV/XRCC4 Complexes. LigIV is stabilized by forming a tight complex with XRCC4 [28]. About 99\% of LigIV is preadenylated when purified together with XRCC4 and it is difficult to readenylate after single-nick ligation [120], implying that the LigIV/XRCC4 complex is ready to ligate DNA. Unlike other human DNA ligases LigIV/XRCC4 can efficiently ligate one of the nicks of a DSB, although the other is unligatable [26], and it can ligate DNA strands across gaps and fully incompatible ends [121]. Furthermore, it has been shown that LigIV can ligate single-stranded poly$T$ DNA [122]. Interestingly, the ligation efficiency is higher with long DNA substrates $\geq 157$ bp than short ones $\leq 53$ bp
[123]. This might be related to the observation that a single LigIV/XRCC4 bridges two DNA ends [124].

The crystal structures of the XRCC4 dimer complexed with the tandem BRCT domain of LigIV shows that the linker between the two BRCT domains is well ordered and forms a helix-loop-helix (HLH) clamp around the coiledcoil $[29,94]$ (Figures 12(a) and 12(b)). The same interaction mode and secondary structure arrangement are observed in the orthologous yeast complex between XRCC4 (Lif1p) and LigIV (Lig4p) [95] (Figure 12(c)). The two BRCT domains in the human and yeast complexes extend the clamp, encircling the coiled-coil domain. The 310 -helix in BRCT1 is located close to the conserved XRCC4 interaction region of the linker (XIR: residue 748-784) between two BRCT domains. The corresponding 310 -helix in BRCT1 of $53 \mathrm{BP} 1$ participates in the interaction surface of $\mathrm{p} 53[125,126]$. The interaction of XRCC4 with LigIV produces a kink in one helix of the coiled-coil of XRCC4 dimer and switches the left-handed heptad repeat into a right-handed undecad coiled-coil; as a result, the LigIV interaction surface becomes flat $[29,94]$. The kink bends in the opposite direction in the complex between XRCC4 with XIR and with the tandem BRCT domain [94]. The former structure might be an intermediate state of LigIV/XRCC4 interaction. If so, this dynamical conformational change might have a biological role in vivo. This kink does not appear in Lif1p/Lig4p even though the refinement of the structure against a new $3.5 \AA$ diffraction data set was carried out (see [127], T Ochi and TL Blundell, unpublished results). Thus, the kink may be unique to human and some other higher organisms.

The second helix in HLH mediates a hydrophobic interaction with the opposite side of the flat surface of the XRCC4 to where XIR interacts [94] and a similar extensive hydrophobic interaction is observed in Lif1p/Lig4 (residues 827-839) [95]. LigIV additionally interacts with the coiled-coil of XRCC 4 via $\alpha^{\prime} 1$ and $\alpha^{\prime} 3$ of BRCT2, in a 


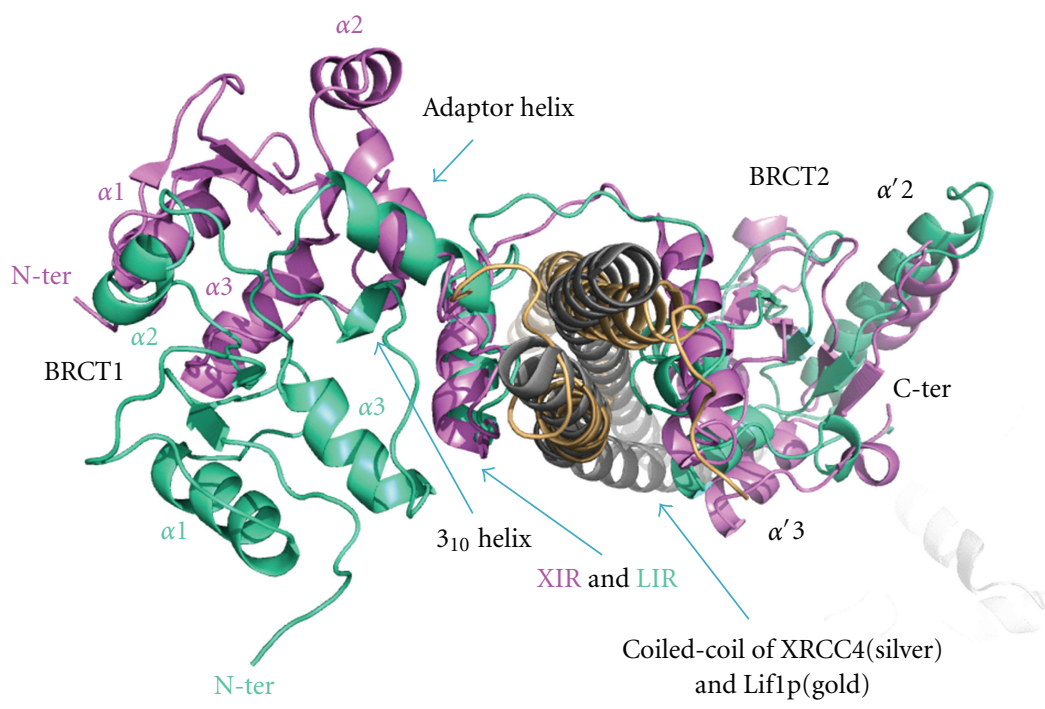

FIGURE 13: Comparison of positions of BRCT1 between LigIV/XRCC4 and Lif1p/Lig4p. Structures of LigIV/XRCC4 (violet/silver) and Lifp1/Lig4p (green/gold) were superimposed based on XIR and LIR. The figure is a view of the C-to N-terminal direction of the coiled-coils of XRCC4 and Lif1p. The N-terminals and helices of BRCT1 of LigIV and Li4p are labeled with violet and green, respectively.

manner that resembles the interaction between BRCT1 and BRCT2 of other tandem BRCT domains. Superposition of LigIV/XRCC4 and Lif1p/Lig4p based on XIR and the corresponding region of Lig4p (LIR) shows that, apart from the kink described above, a further change occurs in the position of BRCT1 (Figure 13). This may be a crystallographic artefact because BRCT1 is closely packed with BRCT2 belonging to another molecule in both human and yeast structures. However, the NMR structure of BRCT1 (PDB code: 2E2W) has the same conformation as the crystallographic one, suggesting at least human BRCT1 and the following linker is likely to have the same conformation in solution.

A recently published EM structure of the LigIV/XRCC4 complex shows the $\mathrm{N}$-terminal of LigIV in proximity to the head domain of XRCC4 [128]. The authors compared two LigIV/XRCC4 constructs, one with the full-length sequences, and the other with a full-length LigIV and a truncated XRCC4 (residues 1-213). From the differences of the two EM images, they determined the position of the C-terminal of XRCC4 and by labelling the hexahistidine tag with gold, they identified the N-terminus of LigIV. Although the authors reconstructed 2D averaged images of LigIV/XRCC4, the 3D reconstruction failed partially because of heterogeneity of the LigIV/XRCC4 conformation. Thus, they proposed that the catalytic region of LigIV is connected to the C-terminal region by a flexible linker and this may have functional importance (see also Perry et al. (2010) [119]).

We have carried out SAXS studies of the tandem BRCT domain of LigIV/mutated XRCC4 (BmX4) and LigIV/mutated XRCC4 (LmX4) in order to investigate the conformation of the catalytic region in solution (Figure 14(a)) [129]. Here, mutated XRCC4 is identical to the one used for solving the structure of XIR/XRCC4 [29]. The linearity of the respective Guinier plots confirmed that the protein solutions were homogeneous and monodisperse
(Figure 14(b)). The deduced radius of gyration and the maximum molecular dimension of LmX4 are $9 \AA$ and $43 \AA$ larger, respectively, than those of $\mathrm{BmX} 4$. The simulated scattering profile using the crystallographic structure of $\mathrm{BmX} 4$ (PDB code: 3II6) fitted the measured SAXS curve well $\left(\chi^{2}=\right.$ 3.687, data not shown). Moreover, the ab initio 3D shape restoration of $\mathrm{BmX} 4$ reproduced an overall conformation consistent with the crystal structure (Figure 14(c)). The $a b$ initio shape reconstruction of $\mathrm{LmX} 4$ revealed that the catalytic region may contribute additional density to the head domain of XRCC4 or the tandem BRCT domain of LigIV when compared with the conformation of BmX4 (Figure 14(c)). Since the extended, open conformation of the catalytic region in solution has also been observed in an archaeal DNA ligase [74], the extra density may correspond to a similar conformation of the catalytic region of LigIV to the closed conformation observed in other archaea DNA ligases $[75,76]$. As the shape restorations of $\mathrm{LmX} 4$ yielded a reproducible conformation (also indicated by the normalized spatial discrepancy (NSD) value after shape averaging), this finding might imply interactions between the catalytic region and BmX4. However, electrophoretic mobility shift assay and protease analysis (data not shown) indicate that the catalytic region is unlikely to have strong interactions with BmX4. Thus, although the majority of LmX4 in solution may have the extended open conformation, the catalytic region is flexibly attached to BmX4. Our observations agree with the EM study [128].

3.3. XLF/XRCC4 Complexes. The interaction between XLF and XRCC4 is salt sensitive, it does not depend on DNA $[39,133]$ and interactions occur through the head regions as shown by yeast two-hybrid study of various mutants [134]. XLF bound to beads at its C-terminal was still able to pull 


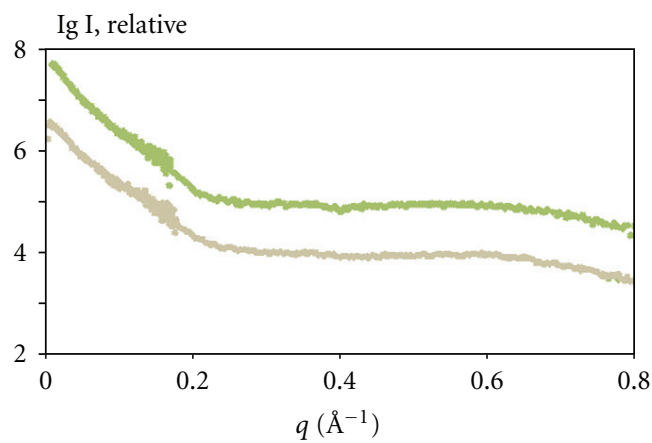

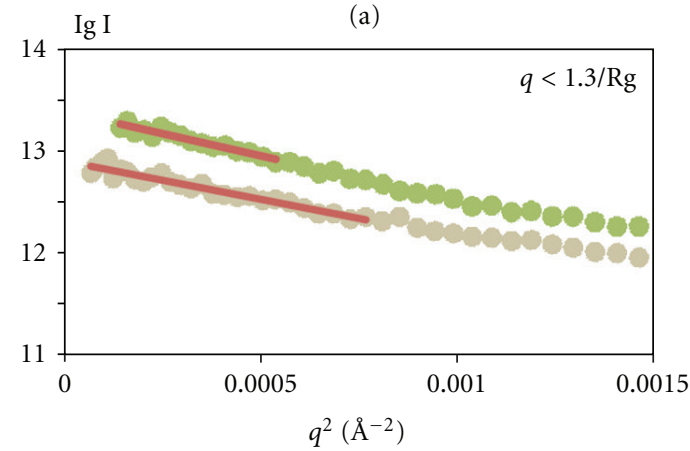

(b)

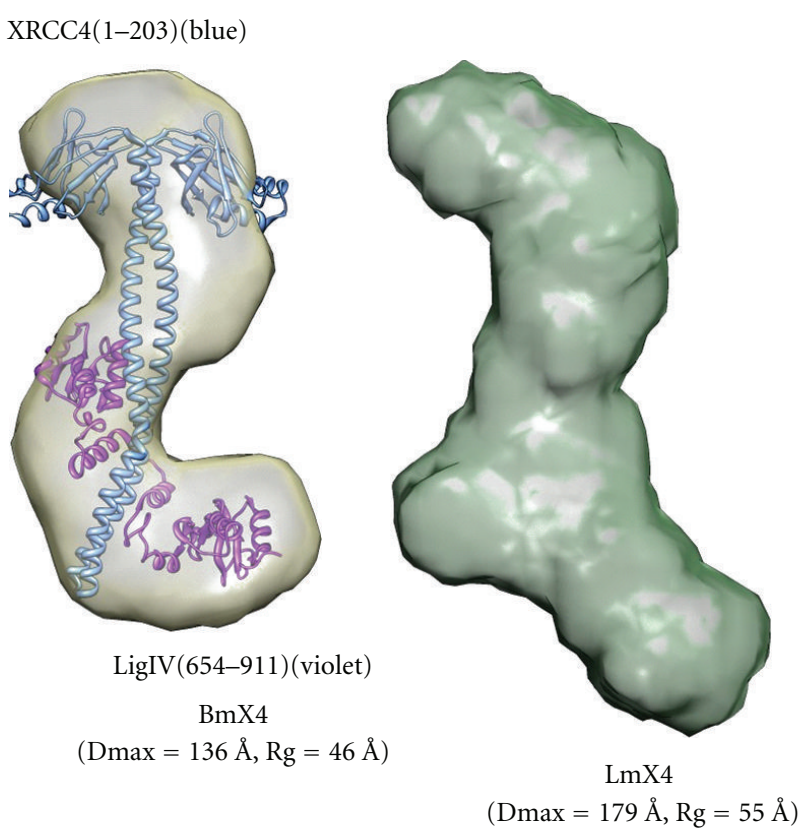

(c)

Figure 14: SAXS study of LmX4 and Bm4. (a) SAXS data of LmX4 (green) and BmX4 (gold) where $q=(4 \pi \sin \theta) / \lambda$. (b) Guinier plots of LmX4 and BmX4 with liner fits (red line) $q<1.3 / \mathrm{Rg}$. (c) Shape reconstructions of BmX4 (gold) and LmX4 (green) created by using Dammin [130]. Ten individual models were calculated and averaged by Damaver [131]. NSD of BmX4 and LmX4 are 0.780 and 0.814, respectively. Molecular envelopes were produced using the UCSF Chimera package from the Resource for Biocomputing, Visualization, and Informatics at the University of California, San Francisco (supported by NIH P41 RR-01081) [132]. The crystallographic model of BmX4 (PDB code: 3II6) was superimposed into its molecular envelope by using Chimera.

down LigIV/XRCC4, implying that the C-terminal of XLF is not important for interaction with LigIV/XRCC4 [135].

Mutagenesis studies indicate that the structurally exposed XLF residue L115 (Figure 16 shown in green) located in the $\beta 6-\beta 7$ loop is important for XLF/XRCC4 interaction [112]. Residues K63, K65, and K99 (Figure 15 shown in green) of XRCC4 are essential for interaction and are located on the region of the head domain close to the helical tail [112]. Nonessential interaction residues of XLF are mainly located outside the head domain region whereas the nonessential XLF/XRCC4 binding residues in XRCC4 are mainly located on the topside of $\mathrm{N}$-terminal head domain and on the helical tail structure before the LigIV binding region (Figures 15 and 16 shown in grey) [112]. These studies are consistent with a linear side-by-side interaction model, in which XLF head domains slide into the space created by XRCC4 head domains and N-terminal part of the tail structure [112] (Figure 17). However, we cannot exclude a model for XLF/XRCC4, involving XLF and XRCC4 binding together in a side-by-side manner but with a degree of twist introducing curvature and possibly a circular complex. This would have the advantage of forming a finite and discrete complex. Further X-ray small angle scattering experiments may be the best approach to resolving this, especially if the complexes are dynamic as gel filtration experiments suggest. However, some encouragement that well-defined complexes can be identified is found in the observation that XLF/XRCC4 complexes have been crystallized and X-ray data collected, albeit to low resolution $(\mathrm{Q} \mathrm{Wu}, \mathrm{TL}$ Blundell unpublished data).

3.4. Spatial Arrangement of Higher-Order Complexes. In order to give a picture of the spatial and temporal organisation of the NHEJ repair system as a whole, an understanding of the order of interactions during the assembly of the DNA-PKcs/Ku70/Ku80/DNA ternary complex and the LigIV/XRCC4/XLF/DNA quaternary complex will be essential.

Ku70/80 and DNA-PKcs, which have higher DNAbinding affinity compared to LigIV/XRCC4/XLF, most likely form the DNA-PKcs/Ku70/Ku80/DNA ternary complex first. For the following LigIV/XRCC4/XLF/DNA complex formation, the order and dynamics of protein assembly are still to be determined. The interaction between XRCC4 and XLF is relatively weak compared to the strong binding between XRCC4 and LigIV. It is not clear whether the XLF-dimer interactions with XRCC4-dimer are maintained when the ligase is recruited. Protein interaction assays have confirmed the XRCC4 independent, XLF recruitment to DSBs ends through interaction with Ku70/80 only in the present of DNA. This may imply that XLF can act independently without XRCC4. 


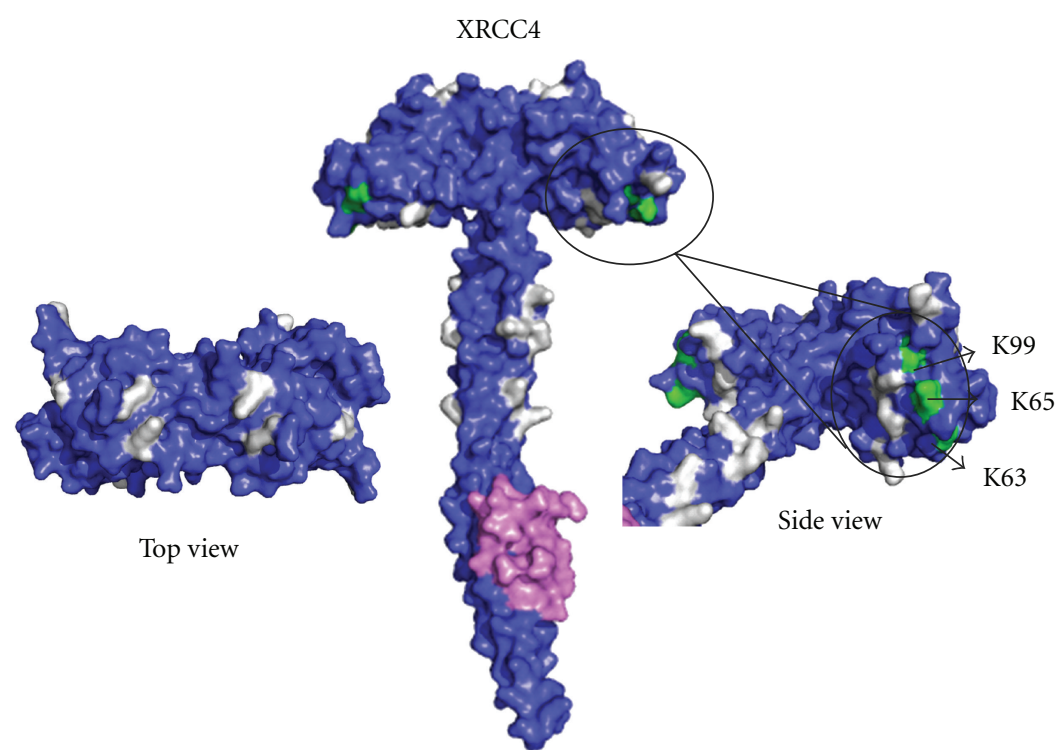

FIGURE 15: Surface views of XRCC4 $4_{1-213}$-DNA ligase IV peptide ${ }_{748-784}$ structure (PDB code:1IK9). Residues K63, K65, and K99, which are important for XLF-XRCC4 binding are labeled in green. Nonessential residues for XLF-XRCC4 interaction K26, R71, K72, K90, R107, K115, K146, R150, R153, R161, and R164 are labeled in grey [112].

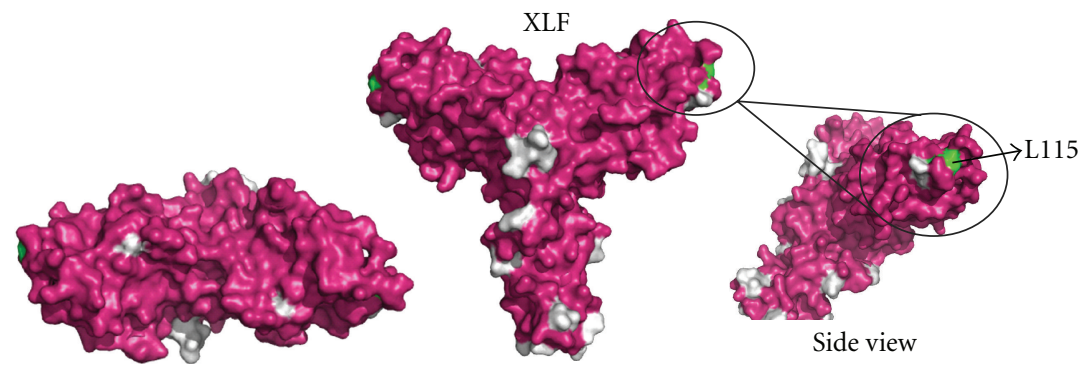

Top view

FIgURE 16: Surface views of $\mathrm{XLF}_{1-233}$ (PDB code: 2QM4). Residue L115, which is important for XLF-XRCC4 binding is labeled in green. Nonessential residues for XLF-XRCC4 interaction I105, E111, E169, L174, R178, L179, E185, and I195 and residues after 224 are labeled in grey [112].

Live cell imaging techniques have identified the immediate recruitment of XLF to laser-induced DSBs with $\mathrm{Ku} 70 / 80$ protein bound [136]. XRCC4 is dispensable for XLF recruitment to DNA ends, but its presence can stabilize the XLF/DNA interaction [136]. Protein interaction assays have confirmed the interaction between Ku70/80 and XLF, and this interaction only occurs in the presence of DNA [136].

Both XRCC4 and XLF require a long piece of DNA for binding. How DNA is structurally involved in all the higher-order protein complexes is of fundamental interest. The phosphorylation of LigIV, XRCC4, and XLF by DNAPKcs does not interfere greatly with the core functions of these proteins, but could alter the relative binding affinities of various protein-protein or protein-DNA interactions, which are important for correct spatial arrangement of the higherorder complexes. All of this uncertainty underlines the need for further studies to characterise complexes temporally as well as spatially.

\section{Discussion}

The challenges of structural characterisation of dynamic multiprotein systems clearly demand a combination of SAXS, EM, X-ray crystallography, and other approaches. All will be advantaged by methods for stabilization and fixation of the complexes. Modified constructs, for example, phospho-mimicking mutation and truncation as well as postmodification, for example, phosphorylation and methylation, need to be explored in order to identify stable complexes. For single particle cryo-EM studies, GraFix has been successfully introduced to stabilize macromolecules [137]. This exploits glycerol gradient centrifugation into increasing concentrations of chemical fixation reagent to stabilize individual macromolecules and to prevent opportunistic aggregation. A similar approach might be used for other structural studies including X-ray crystallography, although here molecular surface modification of the complexes may prevent the formation of ordered crystals. 


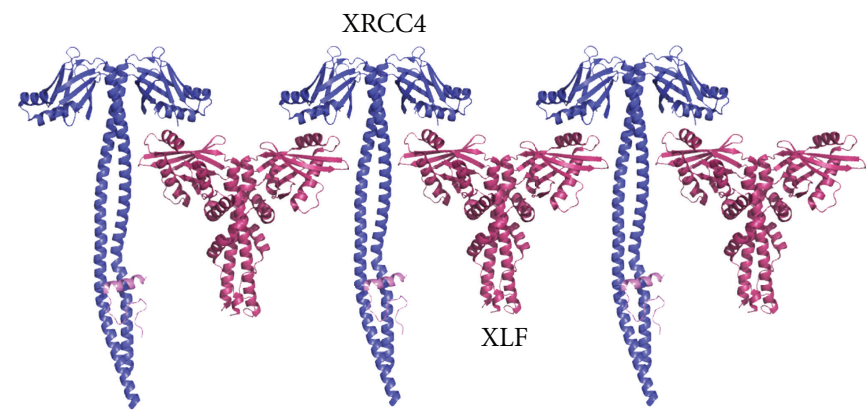

Figure 17: XLF/XRCC4 linear side-by-side interaction model. Adapted from [112].

Crystals of large multiprotein assemblies suitable for high-resolution X-ray diffraction remain a challenge. So the development of methods to analyse low-resolution X-ray diffraction data is essential. In this respect free-electron laser (FEL) light sources may allow single particle X-ray FEL (XFEL) imaging. X-ray crystallography with nanocrystals is also a promising method.

$\mathrm{X}$-ray crystallography is still the only technique to give atomic resolution of large structures and high resolution is essential for studying the binding of small molecules. Indeed chemical tools that allow specific intervention in NHEJ should allow dissection of the roles of the various components. These tools would also likely contribute to the discovery of lead compounds and preclinical candidates for therapeutic intervention at allosteric and other regulatory interaction sites in oncology and for patients with defects in the NHEJ pathway.

The immediate interest, developing from the emerging structure of DNA-PKcs, is the improvement of design of inhibitors that bind at the ATP site of the protein kinase moiety. Such inhibitors would not only inform the development of useful therapeutic agents but should also be of immediate value in investigating the possibility of improving stability of the kinase domain, and the quality and resolution of crystals.

Eventually, we would hope to pursue a structure-guided approach to optimize the design of such inhibitors. Similar approaches could be taken with the ligase active site. In our view a more exciting and adventurous approach would be to design new chemical entities that bind at allosteric sites, templates or adaptor binding sites-so called allotargeting - that are critical to the activation, colocalisation and/or specificity of the regulation of NHEJ. The use of fragment-based methods [138-140] in this context is attractive. Likely targets would be the head-to-head interactions of XRCC4 and XLF, the interactions of BRCT domains, and the interaction of Ku70/80 and the DNA-PKcs.

In conclusion, a spatial and temporal understanding of NHEJ should provide insights into the mechanism of this critical cellular process and also suggest approaches to designing useful chemical tools. Indeed the design of small chemical agents that noncovalently modulate interactions would also likely contribute to the discovery of lead compounds that allow therapeutic intervention in oncology and treatment of patients with defects in the NHEJ pathway.

\section{Acknowledgments}

The authors would like to thank Dr. J. Günter Grossmann for useful discussions and comments on the SAXS data. B. L. Sibanda and D. Y. Chirgadze were supported by Wellcome Trust Programme Grant: 079281/Z/06/Z. T. Ochi was supported by Overseas Research Studentship (ORS). Molecular graphics except for Figures 4 and 14 were prepared by using PyMOL [141].

\section{References}

[1] M. Takata, M. S. Sasaki, E. Sonoda et al., "Homologous recombination and non-homologous end-joining pathways of DNA double-strand break repair have overlapping roles in the maintenance of chromosomal integrity in vertebrate cells," The EMBO Journal, vol. 17, no. 18, pp. 5497-5508, 1998.

[2] M. O'Driscoll and P. A. Jeggo, "The role of double-strand break repair-insights from human genetics," Nature Reviews Genetics, vol. 7, no. 1, pp. 45-54, 2006.

[3] M. M. Vilenchik and A. G. Knudson, "Endogenous DNA double-strand breaks: production, fidelity of repair, and induction of cancer," Proceedings of the National Academy of Sciences of the United States of America, vol. 100, no. 22, pp. 12871-12876, 2003.

[4] K. K. Khanna and S. P. Jackson, "DNA double-strand breaks: signaling, repair and the cancer connection," Nature Genetics, vol. 27, no. 3, pp. 247-254, 2001.

[5] M. Gellert, "V(D)J recombination: RAG proteins, repair factors, and regulation," Annual Review of Biochemistry, vol. 71, pp. 101-132, 2002.

[6] J. Chaudhuri and F. W. Alt, "Class-switch recombination: interplay of transcription, DNA deamination and DNA repair," Nature Reviews Immunology, vol. 4, no. 7, pp. 541552, 2004.

[7] C. T. Yan, C. Boboila, E. K. Souza et al., "IgH class switching and translocations use a robust non-classical end-joining pathway," Nature, vol. 449, no. 7161, pp. 478-482, 2007.

[8] A. Nussenzweig and M. C. Nussenzweig, "A backup DNA repair pathway moves to the forefront," Cell, vol. 131, no. 2, pp. 223-225, 2007.

[9] M. R. Lieber, Y. Ma, U. Pannicke, and K. Schwarz, "The mechanism of vertebrate nonhomologous DNA end joining and its role in $\mathrm{V}(\mathrm{D}) \mathrm{J}$ recombination," DNA Repair, vol. 3, no. 8-9, pp. 817-826, 2004.

[10] J. R. Walker, R. A. Corpina, and J. Goldberg, "Structure of the $\mathrm{Ku}$ heterodimer bound to dna and its implications for 
double-strand break repair," Nature, vol. 412, no. 6847, pp. 607-614, 2001.

[11] J. A. Downs and S. P. Jackson, "A means to a DNA end: the many roles of Ku," Nature Reviews Molecular Cell Biology, vol. 5, no. 5, pp. 367-378, 2004.

[12] K. O. Hartley, D. Gell, G. C. M. Smith et al., "DNAdependent protein Kinase catalytic subunit: a relative of phosphatidylinositol 3-Kinase and the ataxia telangiectasia gene product," Cell, vol. 82, no. 5, pp. 849-856, 1995.

[13] B. K. Singleton, M. I. Torres-Arzayus, S. T. Rottinghaus, G. E. Taccioli, and P. A. Jeggo, "The C terminus of Ku80 activates the DNA-dependent protein Kinase catalytic subunit," Molecular and Cellular Biology, vol. 19, no. 5, pp. 3267-3277, 1999.

[14] D. Gell and S. P. Jackson, "Mapping of protein-protein interactions within the DNA-dependent protein Kinase complex," Nucleic Acids Research, vol. 27, no. 17, pp. 3494-3502, 1999.

[15] S. Yoo and W. S. Dynan, "Geometry of a complex formed by double strand break repair proteins at a single DNA end: recruitment of DNA-PKcs induces inward translocation of Ku protein," Nucleic Acids Research, vol. 27, no. 24, pp. 46794686, 1999.

[16] L. Spagnolo, A. Rivera-Calzada, L. H. Pearl, and O. Llorca, "Three-dimensional structure of the human DNA$\mathrm{PKcs} / \mathrm{Ku} 70 / \mathrm{Ku} 80$ complex assembled on DNA and its implications for DNA DSB repair," Molecular Cell, vol. 22, no. 4, pp. 511-519, 2006.

[17] G. C. M. Smith and S. P. Jackson, "The DNA-dependent protein Kinase," Genes and Development, vol. 13, no. 8, pp. 916-934, 1999.

[18] E. Weterings and D. J. Chen, "The endless tale of nonhomologous end-joining," Cell Research, vol. 18, no. 1, pp. 114-124, 2008.

[19] Q. Ding, Y. V. R. Reddy, W. Wang et al., “Autophosphorylation of the catalytic subunit of the DNA-dependent protein Kinase is required for efficient end processing during DNA double-strand break repair," Molecular and Cellular Biology, vol. 23, no. 16, pp. 5836-5848, 2003.

[20] W. D. Block, Y. Yu, D. Merkle et al., "Autophosphorylationdependent remodeling of the DNA-dependent protein Kinase catalytic subunit regulates ligation of DNA ends," Nucleic Acids Research, vol. 32, no. 14, pp. 4351-4357, 2004.

[21] D. Moshous, I. Callebaut, R. de Chasseval et al., "Artemis, a novel DNA double-strand break repair/V(D)J recombination protein, is mutated in human severe combined immune deficiency," Cell, vol. 105, no. 2, pp. 177-186, 2001.

[22] M. R. Lieber, "The mechanism of double-strand DNA break repair by the nonhomologous DNA end-joining pathway," Annual Review of Biochemistry, vol. 79, pp. 181-211, 2010.

[23] Y. Ma, U. Pannicke, K. Schwarz, and M. R. Lieber, "Hairpin opening and overhang processing by an Artemis/DNAdependent protein Kinase complex in nonhomologous end joining and V(D)J recombination," Cell, vol. 108, no. 6, pp. 781-794, 2002.

[24] K. N. Mahajan, S. A. Nick McElhinny, B. S. Mitchell, and D. A. Ramsden, "Association of DNA polymerase $\mu(\operatorname{pol} \mu)$ with $\mathrm{Ku}$ and ligase IV: role for pol $\mu$ in end-joining double-strand break repair," Molecular and Cellular Biology, vol. 22, no. 14, pp. 5194-5202, 2002.

[25] J. W. Lee, L. Blanco, T. Zhou et al., "Implication of DNA Polymerase $\lambda$ in alignment-based gap filling for nonhomologous DNA end hoining in human nuclear extracts," The Journal of Biological Chemistry, vol. 279, no. 1, pp. 805-811, 2004.
[26] Y. Ma, H. Lu, B. Tippin et al., "A biochemically defined system for mammalian nonhomologous DNA end joining," Molecular Cell, vol. 16, no. 5, pp. 701-713, 2004.

[27] S. A. Roberts, N. Strande, M. D. Burkhalter et al., "Ku is a $5^{\prime}$-dRP/AP lyase that excises nucleotide damage near broken ends," Nature, vol. 464, no. 7292, pp. 1214-1217, 2010.

[28] M. Bryans, M. C. Valenzano, and T. D. Stamato, "Absence of DNA ligase IV protein in XR-1 cells: evidence for stabilization by XRCC4," Mutation Research/DNA Repair, vol. 433, no. 1, pp. 53-58, 1999.

[29] B. L. Sibanda, S. E. Critchlow, J. Begun et al., "Crystal structure of an Xrcc4-DNA ligase IV complex," Nature Structural Biology, vol. 8, no. 12, pp. 1015-1019, 2001.

[30] U. Grawunder, M. Wilm, X. Wu et al., "Activity of DNA ligase IV stimulated by complex formation with XRCC4 protein in mammalian cells," Nature, vol. 388, no. 6641, pp. 492-495, 1997.

[31] M. Modesti, J. E. Hesse, and M. Gellert, "DNA binding of $\mathrm{Xrcc} 4$ protein is associated with $\mathrm{V}(\mathrm{D}) \mathrm{J}$ recombination but not with stimulation of DNA ligase IV activity," The EMBO Journal, vol. 18, no. 7, pp. 2008-2018, 1999.

[32] Y. Wang, B. J. Lamarche, and M.-D. Tsai, "Human DNA ligase IV and the ligase IV/XRCC4 complex: analysis of nick ligation fidelity," Biochemistry, vol. 46, no. 17, pp. 4962-4976, 2007.

[33] Y. Gao, Y. Sun, K. M. Frank et al., "A critical role for DNA end-joining proteins in both lymphogenesis and neurogenesis," Cell, vol. 95, no. 7, pp. 891-902, 1998.

[34] K. M. Frank, J. M. Sekiguchi, K. J. Seidl et al., "Late embryonic lethality and impaired $\mathrm{V}(\mathrm{D}) \mathrm{J}$ recombination in mice lacking DNA ligase IV," Nature, vol. 396, no. 6707, pp. 173-177, 1998.

[35] Y. Gao, D. O. Ferguson, W. Xie et al., "Interplay of p53 and DNA-repair protein XRCC4 in tumorigenesis, genomic stability and development," Nature, vol. 404, no. 6780, pp. 897-900, 2000.

[36] K. M. Frank, N. E. Sharpless, Y. Gao et al., "DNA ligase IV deficiency in mice leads to defective neurogenesis and embryonic lethality via the p53 pathway," Molecular Cell, vol. 5, no. 6, pp. 993-1002, 2000.

[37] M. O’Driscoll, K. M. Cerosaletti, P.-M. Girard et al., "DNA ligase IV mutations identified in patients exhibiting developmental delay and immunodeficiency," Molecular Cell, vol. 8, no. 6, pp. 1175-1185, 2001.

[38] D. Buck, L. Malivert, R. de Chasseval et al., "Cernunnos, a novel nonhomologous end-joining factor, is mutated in human immunodeficiency with microcephaly," Cell, vol. 124, no. 2, pp. 287-299, 2006.

[39] P. Ahnesorg, P. Smith, and S. P. Jackson, "XLF interacts with the XRCC4-DNA Ligase IV complex to promote DNA nonhomologous end-joining," Cell, vol. 124, no. 2, pp. 301313, 2006.

[40] E. Feldmann, V. Schmiemann, W. Goedecke, S. Reichenberger, and P. Pfeiffer, "DNA double-strand break repair in cell-free extracts from Ku80-deficient cells: implications for $\mathrm{Ku}$ serving as an alignment factor in non-homologous DNA end joining," Nucleic Acids Research, vol. 28, no. 13, pp. 25852596, 2000.

[41] M. A. Larkin, G. Blackshields, N. P. Brown et al., "Clustal W and Clustal X version 2.0," Bioinformatics, vol. 23, no. 21, pp. 2947-2948, 2007.

[42] P. Gouet, E. Courcelle, D. I. Stuart, and F. Métoz, "ESPript: analysis of multiple sequence alignments in PostScript," Bioinformatics, vol. 15, no. 4, pp. 305-308, 1999. 
[43] W. S. Dynan and S. Yoo, "Interaction of Ku protein and DNAdependent protein Kinase catalytic subunit with nucleic acids," Nucleic Acids Research, vol. 26, no. 7, pp. 1551-1559, 1998.

[44] C. Y. Chiu, R. B. Cary, D. J. Chen, S. R. Peterson, and P. L. Stewart, "Cryo-EM imaging of the catalytic subunit of the DNA-dependent protein Kinase," Journal of Molecular Biology, vol. 284, no. 4, pp. 1075-1081, 1998.

[45] K. K. Leuther, O. Hammarsten, R. D. Kornberg, and G. Chu, "Structure of DNA-dependent protein Kinase: implications for its regulation by DNA," The EMBO Journal, vol. 18, no. 5, pp. 1114-1123, 1999.

[46] A. Rivera-Calzada, J. D. Maman, L. Spagnolo, L. H. Pearl, and O. Llorca, "Three-dimensional structure and regulation of the DNA-dependent protein Kinase catalytic subunit (DNAPKcs)," Structure, vol. 13, no. 243, p. 495, 2005.

[47] D. R. Williams, K .J. Lee, D. J. Chen, J. Shi, and P. L. Stewart, "Cryo-EM structure of the DNA-dependent protein Kinase catalytic subunit at subnanometer resolution reveals alpha helices and insight into DNA binding," Structure, vol. 16, pp. 468-477, 2008.

[48] B. L. Sibanda, D. Y. Chirgadze, and T. L. Blundell, "Crystal structure of DNA-PKcs reveals a large open-ring cradle comprised of HEAT repeats," Nature, vol. 463, no. 7277, pp. 118-121, 2010.

[49] A. Fujimori, R. Araki, R. Fukumura et al., "Identification of four highly conserved regions in DNA-PKcs," Immunogenetics, vol. 51, no. 11, pp. 965-973, 2000.

[50] C. Xiaoping, Y. Yaping, S. Gupta, Y.-M. Cho, S. P. Lees-Miller, and K. Meek, "Autophosphorylation of DNA-dependent protein Kinase regulates DNA end processing and may also alter double-strand break repair pathway choice," Molecular and Cellular Biology, vol. 25, no. 24, pp. 10842-10852, 2005.

[51] P. Douglas, G. P. Sapkota, N. Morrice et al., "Identification of in vitro and in vivo phosphorylation sites in the catalytic subunit of the DNA-dependent protein Kinase," The Biochemical Journal, vol. 368, no. 1, pp. 243-251, 2002.

[52] Y. Ma, U. Pannicke, H. Lu, D. Niewolik, K. Schwarz, and M. R. Lieber, "The DNA-dependent protein Kinase catalytic subunit phosphorylation sites in human artemis," The Journal of Biological Chemistry, vol. 280, no. 40, pp. 33839-33846, 2005.

[53] P. Douglas, X. Cui, W. D. Block et al., "The DNA-dependent protein Kinase catalytic subunit is phosphorylated in vivo on threonine 3950, a highly conserved amino acid in the protein Kinase domain," Molecular and Cellular Biology, vol. 27, no. 5, pp. 1581-1591, 2007.

[54] M. Le Romancer, S. C. Cosulich, S. P. Jackson, and P. R. Clarke, "Cleavage and inactivation of DNA-dependent protein Kinase catalytic subunit during apoptosis in Xenopus egg extracts," Journal of Cell Science, vol. 109, no. 13, pp. 3121-3127, 1996.

[55] Q. Song, S. P. Lees-Miller, S. Kumar et al., "DNA-dependent protein Kinase catalytic subunit: a target for an ICE-like protease in apoptosis," The EMBO Journal, vol. 15, no. 13, pp. 3238-3246, 1996.

[56] H. Teraoka, Y. Yumoto, F. Watanabe et al., "CPP32/Yama/apopain cleaves the catalytic component of DNA-dependent protein Kinase in the holoenzyme," The FEBS Letters, vol. 393, no. 1, pp. 1-6, 1996.

[57] S. Kumar, P. Pandey, A. Bharti et al., "Regulation of DNAdependent protein Kinase by the Lyn tyrosine Kinase," The Journal of Biological Chemistry, vol. 273, no. 40, pp. 25654 25658, 1998.
[58] U. Yavuzer, G. C. M. Smith, T. Bliss, D. Werner, and S. P. Jackson, "DNA end-independent activation of DNA-PK mediated via association with the DNA-binding protein C1D," Genes and Development, vol. 12, no. 14, pp. 2188-2199, 1998.

[59] T. Wechsler, B. P. C. Chen, R. Harper et al., "DNA-PKcs function regulated specifically by protein phosphatase 5," Proceedings of the National Academy of Sciences of the United States of America, vol. 101, no. 5, pp. 1247-1252, 2004.

[60] S. Jin, S. Kharbanda, B. Mayer, D. Kufe, and D. T. Weaver, "Binding of $\mathrm{Ku}$ and $\mathrm{c}-\mathrm{Abl}$ at the Kinase homology region of DNA-dependent protein Kinase catalytic subunit," The Journal of Biological Chemistry, vol. 272, no. 40, pp. 2476324766, 1997.

[61] X. Wu and M. R. Lieber, "Interaction between DNAdependent protein Kinase and a novel protein, KIP," Mutation Research/DNA Repair, vol. 385, no. 1, pp. 13-20, 1997.

[62] R. Bosotti, A. Isacchi, and E. L. L. Sonnhammer, "FAT: a novel domain in PIK-related Kinases," Trends in Biochemical Sciences, vol. 25, no. 5, pp. 225-227, 2000.

[63] M. Hammel, Y. Yu, B. L. Mahaney et al., "Ku and DNA-dependent protein Kinase dynamic conformations and assembly regulate DNA binding and the initial nonhomologous end joining complex," The Journal of Biological Chemistry, vol. 285, no. 2, pp. 1414-1423, 2010.

[64] A. J. Doherty and S. W. Suh, "Structural and mechanistic conservation in DNA ligases," Nucleic Acids Research, vol. 28, no. 21, pp. 4051-4058, 2000.

[65] T. Ellenberger and A. E. Tomkinson, "Eukaryotic DNA ligases: structural and functional insights," Annual Review of Biochemistry, vol. 77, pp. 313-338, 2008.

[66] J. M. Pascal, "DNA and RNA ligases: structural variations and shared mechanisms," Current Opinion in Structural Biology, vol. 18, no. 1, pp. 96-105, 2008.

[67] S. Shuman, "DNA ligases: progress and prospects," The Journal of Biological Chemistry, vol. 284, no. 26, pp. 1736517369, 2009.

[68] S. Shuman and C. D. Lima, "The polynucleotide ligase and RNA capping enzyme superfamily of covalent nucleotidyltransferases," Current Opinion in Structural Biology, vol. 14, no. 6, pp. 757-764, 2004.

[69] S. Shuman and B. Schwer, "RNA capping enzyme and DNA ligase: a superfamily of covalent nucleotidyl transferases," Molecular Microbiology, vol. 17, no. 3, pp. 405-410, 1995.

[70] C. Marchetti, S. A. Walker, F. Odreman, A. Vindigni, A. J. Doherty, and P. Jeggo, "Identification of a novel motif in DNA ligases exemplified by DNA ligase IV," DNA Repair, vol. 5, no. 7, pp. 788-798, 2006.

[71] A. G. Murzin, "OB(oligonucleotide/oligosaccharide binding)-fold: common structural and functional solution for non-homologous sequences," The EMBO Journal, vol. 12, no. 3, pp. 861-867, 1993.

[72] D. A. Chistiakov, N. V. Voronova, and A. P. Chistiakov, "Ligase IV syndrome," European Journal of Medical Genetics, vol. 52, no. 6, pp. 373-378, 2009.

[73] J. M. Pascal, P. J. O'Brien, A. E. Tomkinson, and T. Ellenberger, "Human DNA ligase I completely encircles and partially unwinds nicked DNA," Nature, vol. 432, no. 7016, pp. 473-478, 2004.

[74] J. M. Pascal, O. V. Tsodikov, G. L. Hura et al., "A flexible interface between DNA Ligase and PCNA supports conformational switching and efficient ligation of DNA," Molecular Cell, vol. 24, no. 2, pp. 279-291, 2006. 
[75] H. Nishida, S. Kiyonari, Y. Ishino, and K. Morikawa, "The closed structure of an archaeal DNA Ligase from pyrococcus furiosus," Journal of Molecular Biology, vol. 360, no. 5, pp. 956-967, 2006.

[76] D. J. Kim, O. Kim, H.-W. Kim, H. S. Kim, S. J. Lee, and S. W. Suh, "ATP-dependent DNA ligase from archaeoglobus fulgidus displays a tightly closed conformation," Acta Crystallographica Section F, vol. 65, no. 6, pp. 544-550, 2009.

[77] I. V. Martin and S. A. MacNeill, "ATP-dependent DNA ligases," Genome Biology, vol. 3, no. 4, article 3005, 2002.

[78] E. Cotner-Gohara, I.-K. Kim, A. E. Tomkinson, and T. Ellenberger, "Two DNA-binding and nick recognition modules in human DNA ligase III," The Journal of Biological Chemistry, vol. 283, no. 16, pp. 10764-10772, 2008.

[79] A. E. Tomkinson, S. Vijayakumar, J. M. Pascal, and T. Ellenberger, "DNA ligases: structure, reaction mechanism, and function," Chemical Reviews, vol. 106, no. 2, pp. 687-699, 2006.

[80] U. Grawunder, D. Zimmer, and M. R. Lieber, "DNA ligase IV binds to XRCC4 via a motif located between rather than within its BRCT domains," Current Biology, vol. 8, no. 15, pp. 873-876, 1998.

[81] Y.-G. Wang, C. Nnakwe, W. S. Lane, M. Modesti, and K. M. Frank, "Phosphorylation and regulation of DNA ligase IV stability by DNA-dependent protein Kinase," The Journal of Biological Chemistry, vol. 279, no. 36, pp. 37282-37290, 2004.

[82] X. Zhang, S. Moréra, P. A. Bates et al., "Structure of an XRCC1 BRCT domain: a new protein-protein interaction module," The EMBO Journal, vol. 17, no. 21, pp. 6404-6411, 1998.

[83] P. Bork, K. Hofmann, P. Bucher, A. F. Neuwald, S. F. Altschul, and E. V. Koonin, "A superfamily of conserved domains in DNA damage-responsive cell cycle checkpoint proteins," The FASEB Journal, vol. 11, no. 1, pp. 68-76, 1997.

[84] S. Costantini, L. Woodbine, L. Andreoli, P. A. Jeggo, and A. Vindigni, "Interaction of the Ku heterodimer with the DNA ligase IV/Xrcc4 complex and its regulation by DNAPK," DNA Repair, vol. 6, no. 6, pp. 712-722, 2007.

[85] E. N. Shiozaki, L. Gu, N. Yan, and Y. Shi, "Structure of the BRCT repeats of BRCA1 bound to a BACH1 phosphopeptide: implications for signaling," Molecular Cell, vol. 14, no. 3, pp. 405-412, 2004.

[86] J. A. Clapperton, I. A. Manke, D. M. Lowery et al., "Structure and mechanism of BRCA1 BRCT domain recognition of phosphorylated BACH1 with implications for cancer," Nature Structural and Molecular Biology, vol. 11, no. 6, pp. 512-518, 2004.

[87] R. S. Williams, M. S. Lee, D. D. Hau, and J. N. M. Glover, "Structural basis of phosphopeptide recognition by the BRCT domain of BRCA1," Nature Structural and Molecular Biology, vol. 11, no. 6, pp. 519-525, 2004.

[88] M. Stucki, J. A. Clapperton, D. Mohammad, M. B. Yaffe, S. J. Smerdon, and S. P. Jackson, "MDC1 directly binds phosphorylated histone $\mathrm{H} 2 \mathrm{AX}$ to regulate cellular responses to DNA double-strand breaks," Cell, vol. 123, no. 7, pp. 12131226, 2005.

[89] A. K. Varma, R. S. Brown, G. Birrane, and J. A. A. Ladias, "Structural basis for cell cycle checkpoint control by the BRCA1-CtIP complex," Biochemistry, vol. 44, no. 33, pp. 10941-10946, 2005.

[90] M. L. Kilkenny, A. S. Doré, S. M. Roe et al., "Structural and functional analysis of the Crb2-BRCT2 domain reveals distinct roles in checkpoint signaling and DNA damage repair," Genes and Development, vol. 22, no. 15, pp. 20342047, 2008.

[91] R. S. Williams, G. E. Dodson, O. Limbo et al., "Nbs1 flexibly tethers Ctp1 and Mre11-Rad50 to coordinate DNA doublestrand break processing and repair," Cell, vol. 139, no. 1, pp. 87-99, 2009.

[92] J. Lloyd, J. R. Chapman, J. A. Clapperton et al., “A Supramodular FHA/BRCT-repeat architecture mediates Nbs1 adaptor function in response to DNA damage," Cell, vol. 139, no. 1, pp. 100-111, 2009.

[93] J. S. Williams, R. S. Williams, C. L. Dovey, G. Guenther, J. A. Tainer, and P. Russell, " $\gamma \mathrm{h} 2 \mathrm{~A}$ binds Brc1 to maintain genome integrity during S-phase," The EMBO Journal, vol. 29, no. 6, pp. 1136-1148, 2010.

[94] P.-Y. Wu, P. Frit, S. Meesala et al., "Structural and functional interaction between the human DNA repair proteins DNA ligase IV and XRCC4," Molecular and Cellular Biology, vol. 29, no. 11, pp. 3163-3172, 2009.

[95] A. S. Doré, N. Furnham, O. R. Davies et al., "Structure of an Xrcc4-DNA ligase IV yeast ortholog complex reveals a novel BRCT interaction mode," DNA Repair, vol. 5, no. 3, pp. 362368, 2006.

[96] X. Yu, C. C. S. Chini, M. He, G. Mer, and J. Chen, "The BRCT domain is a phospho-protein binding domain," Science, vol. 302, no. 5645, pp. 639-642, 2003.

[97] M. Rodriguez, X. Yu, J. Chen, and Z. Songyang, "Phosphopeptide binding specificities of BRCA1 COOH-terminal (BRCT) domains," The Journal of Biological Chemistry, vol. 278, no. 52, pp. 52914-52918, 2003.

[98] J. N. M. Glover, R. S. Williams, and M. S. Lee, "Interactions between BRCT repeats and phosphoproteins: tangled up in two," Trends in Biochemical Sciences, vol. 29, no. 11, pp. 579$585,2004$.

[99] K. Imami, N. Sugiyama, Y. Kyono, M. Tomita, and Y. Ishihama, "Automated phosphoproteome analysis for cultured cancer cells by two-dimensional nanoLC-MS using a calcined titania/C18 biphasic column," Analytical Sciences, vol. 24, no. 1, pp. 161-166, 2008.

[100] S. Unal, K. Cerosaletti, D. Uckan-Cetinkaya, M. Cetin, and F. Gumruk, "A novel mutation in a family with DNA ligase IV deficiency syndrome," Pediatric Blood and Cancer, vol. 53, no. 3, pp. 482-484, 2009.

[101] Y. Li, D. Y. Chirgadze, V. M. Bolanos-Garcia et al., "Crystal structure of human XLF/Cernunnos reveals unexpected differences from XRCC4 with implications for NHEJ," The EMBO Journal, vol. 27, no. 1, pp. 290-300, 2008.

[102] M. Modesti, M. S. Junop, R. Ghirlando et al., "Tetramerization and DNA ligase IV interaction of the DNA doublestrand break repair protein XRCC4 are mutually exclusive," Journal of Molecular Biology, vol. 334, no. 2, pp. 215-228, 2003.

[103] M. S. Junop, M. Modesti, A. Guarné, R. Ghirlando, M. Gellert, and W. Yang, "Crystal structure of the Xrcc4 DNA repair protein and implications for end joining," The EMBO Journal, vol. 19, no. 22, pp. 5962-5970, 2000.

[104] M. A. Recuero-Checa, A. S. Doré, E. Arias-Palomo et al., "Electron microscopy of Xrcc4 and the DNA ligase IV-Xrcc4 DNA repair complex," DNA Repair, vol. 8, no. 12, pp. 13801389, 2009.

[105] R. Mizuta, H.-L. Cheng, Y. Gao, and F. W. Alt, "Molecular genetic characterization of XRCC4 function," International Immunology, vol. 9, no. 10, pp. 1607-1613, 1997.

[106] Y. Yu, W. Wang, Q. Ding et al., "DNA-PK phosphorylation sites in XRCC4 are not required for survival after radiation 
or for $\mathrm{V}(\mathrm{D}) \mathrm{J}$ recombination," DNA Repair, vol. 2, no. 11, pp. 1239-1252, 2003.

[107] C. A. Koch, R. Agyei, S. Galicia et al., "Xrcc4 physically links DNA end processing by polynucleotide Kinase to DNA ligation by DNA ligase IV," The EMBO Journal, vol. 23, no. 19, pp. 3874-3885, 2004.

[108] N. K. Bernstein, R. S. Williams, M. L. Rakovszky et al., "The molecular architecture of the mammalian DNA repair enzyme, polynucleotide Kinase," Molecular Cell, vol. 17, no. 5, pp. 657-670, 2005.

[109] V. Yurchenko, Z. Xue, and M. J. Sadofsky, "SUMO modification of human XRCC4 regulates its localization and function in DNA double-strand break repair," Molecular and Cellular Biology, vol. 26, no. 5, pp. 1786-1794, 2006.

[110] Y. Dai, B. Kysela, L. A. Hanakahi et al., "Nonhomologous end joining and $\mathrm{V}(\mathrm{D}) \mathrm{J}$ recombination require an additional factor," Proceedings of the National Academy of Sciences of the United States of America, vol. 100, no. 5, pp. 2462-2467, 2003.

[111] P. Hentges, P. Ahnesorg, R. S. Pitcher et al., "Evolutionary and functional conservation of the DNA non-homologous endjoining protein, XLF/Cernunnos," The Journal of Biological Chemistry, vol. 281, no. 49, pp. 37517-37526, 2006.

[112] S. N. Andres, M. Modesti, C. J. Tsai, G. Chu, and M. S. Junop, "Crystal structure of human XLF: a twist in nonhomologous DNA end-joining," Molecular Cell, vol. 28, no. 6, pp. 10931101, 2007.

[113] C. J. Tsai, S. A. Kim, and G. Chu, "Cernunnos/XLF promotes the ligation of mismatched and noncohesive DNA ends," Proceedings of the National Academy of Sciences of the United States of America, vol. 104, no. 19, pp. 7851-7856, 2007.

[114] K. Akopiants, R.-Z. Zhou, S. Mohapatra et al., "Requirement for XLF/Cernunnos in alignment-based gap filling by DNA polymerases $\lambda$ and $\mu$ for nonhomologous end joining in human whole-cell extracts," Nucleic Acids Research, vol. 37, no. 12, pp. 4055-4062, 2009.

[115] R. Harris, D. Esposito, A. Sankar et al., "The 3D solution structure of the C-terminal region of Ku86 (Ku86CTR)," Journal of Molecular Biology, vol. 335, no. 2, pp. 573-582, 2004.

[116] Z. Zhang, W. Hu, L. Cano, T. D. Lee, D. J. Chen, and Y. Chen, "Solution structure of the C-terminal domain of Ku80 suggests important sites for protein-protein interactions," Structure, vol. 12, no. 3, pp. 495-502, 2004.

[117] A. Rivera-Calzada, L. Spagnolo, L. H. Pearl, and O. Llorca, "Structural model of full-length human Ku70-Ku80 heterodimer and its recognition of DNA and DNA-PKcs," EMBO Reports, vol. 8, no. 1, pp. 56-62, 2007.

[118] J. Boskovic, A. Rivera-Calzada, J. D. Maman et al., "Visualization of DNA-induced conformational changes in the DNA repair Kinase DNA-PKcs," The EMBO Journal, vol. 22, no. 21, pp. 5875-5882, 2003.

[119] J. J. Perry, E. Cotner-gohara, T. Ellenberger, and J. A. Tainer, "Structural dynamics in DNA damage signaling and repair," Current Opinion in Structural Biology, vol. 20, no. 3, pp. 283294, 2010

[120] X. Chen, J. D. Ballin, J. Della-Maria et al., "Distinct kinetics of human DNA ligases I, III $\alpha$, III $\beta$, and IV reveal direct DNA sensing ability and differential physiological functions in DNA repair," DNA Repair, vol. 8, no. 8, pp. 961-968, 2009.

[121] J. Gu, H. Lu, B. Tippin, N. Shimazaki, M. F. Goodman, and M. R. Lieber, "XRCC4:DNA ligase IV can ligate incompatible DNA ends and can ligate across gaps," The EMBO Journal, vol. 26, no. 4, pp. 1010-1023, 2007.
[122] J. Gu, H. Lu, A. G. Tsai, K. Schwarz, and M. R. Lieber, "Singlestranded DNA ligation and XLF-stimulated incompatible DNA end ligation by the XRCC4-DNA ligase IV complex: influence of terminal DNA sequence," Nucleic Acids Research, vol. 35, no. 17, pp. 5755-5762, 2007.

[123] B. Kysela, A. J. Doherty, M. Chovanec et al., "Ku stimulation of DNA ligase IV-dependent ligation requires inward movement along the DNA molecule," The Journal of Biological Chemistry, vol. 278, no. 25, pp. 22466-22474, 2003.

[124] L. Chen, K. Trujillo, P. Sung, and A. E. Tomkinson, "Interactions of the DNA ligase IV-XRCC4 complex with DNA ends and the DNA-dependent protein Kinase," The Journal of Biological Chemistry, vol. 275, no. 34, pp. 26196-26205, 2000.

[125] W. S. Joo, P. D. Jeffrey, S. B. Cantor, M. S. Finnin, D. M. Livingston, and N. P. Pavletich, "Structure of the 53BP1 BRCT region bound to $\mathrm{p} 53$ and its comparison to the Brcal BRCT structure," Genes and Development, vol. 16, no. 5, pp. 583-593, 2002.

[126] D. J. Derbyshire, B. P. Basu, L. C. Serpell et al., "Crystal structure of human 53BP1 BRCT domains bound to p53 tumour suppressor," The EMBO Journal, vol. 21, no. 14, pp. 3863-3872, 2002.

[127] T. Ochi, V.M. Bolanos-Garcia, V. Stojanoff, and A. Moreno, "Perspectives on protein crystallisation," Progress in Biophysics and Molecular Biology, vol. 101, no. 1-3, pp. 56-63, 2009.

[128] M. A. Recuero-Checa, A. S. Doré, E. Arias-Palomo et al., "Electron microscopy of Xrcc4 and the DNA ligase IV-Xrcc4 DNA repair complex," DNA Repair, vol. 8, no. 12, pp. 13801389, 2009.

[129] T. Ochi, J. G. Grossmann, V. M. Bolanos-Garcia, and T. L. Blundell, To be published.

[130] D. I. Svergun, "Restoring Low Resolution Structure of Biological Macromolecules from Solution Scattering Using Simulated Annealing," Biophysical journal, vol. 76, pp. 28792886, 1999.

[131] V. V. Volkov and D. I. Svergun, "Uniqueness of ab initio shape determination in small-angle scattering," Journal of Applied Crystallography, vol. 36, no. 3 I, pp. 860-864, 2003.

[132] E. F. Pettersen, T. D. Goddard, C. C. Huang et al., "UCSF Chimera-a visualization system for exploratory research and analysis," Journal of Computational Chemistry, vol. 25, no. 13, pp. 1605-1612, 2004.

[133] E. Riballo, L. Woodbine, T. Stiff, S. A. Walker, A. A. Goodarzi, and P. A. Jeggo, "XLF-Cernunnos promotes DNA ligase IV-XRCC4 re-adenylation following ligation," Nucleic Acids Research, vol. 37, no. 2, pp. 482-492, 2009.

[134] R. A. Deshpande and T. E. Wilson, "Modes of interaction among yeast Nej1, Lif1 and Dnl4 proteins and comparison to human XLF, XRCC4 and Lig4," DNA Repair, vol. 6, no. 10, pp. 1507-1516, 2007.

[135] H. Lu, U. Pannicke, K. Schwarz, and M. R. Lieber, "Lengthdependent binding of human XLF to DNA and stimulation of XRCC4-DNA ligase IV activity," The Journal of Biological Chemistry, vol. 282, no. 15, pp. 11155-11162, 2007.

[136] K.-I. Yano and D. J. Chen, "Live cell imaging of XLF and XRCC4 reveals a novel view of protein assembly in the nonhomologous end-joining pathway," Cell Cycle, vol. 7, no. 10, pp. 1321-1325, 2008.

[137] B. Kastner, N. Fischer, M. M. Golas et al., "GraFix: sample preparation for single-particle electron cryomicroscopy," Nature Methods, vol. 5, no. 1, pp. 53-55, 2008. 
[138] T. L. Blundell, H. Jhoti, and C. Abell, "High-throughput crystallography for lead discovery in drug design," Nature Reviews Drug Discovery, vol. 1, no. 1, pp. 45-54, 2002.

[139] T. L. Blundell, B. L. Sibanda, R. W. Montalvão et al., "Structural biology and bioinformatics in drug design: opportunities and challenges for target identification and lead discovery," Philosophical Transactions of the Royal Society B, vol. 361, no. 1467, pp. 413-423, 2006.

[140] M. Congreve, C. W. Murray, and T. L. Blundell, "Keynote review: structural biology and drug discovery," Drug Discovery Today, vol. 10, no. 13, pp. 895-907, 2005.

[141] W. L. DeLano, The PyMOL Molecular Graphics System, DeLano Scientific LLC, Palo Alto, Calif, USA, 2008, http://www.pymol.org. 

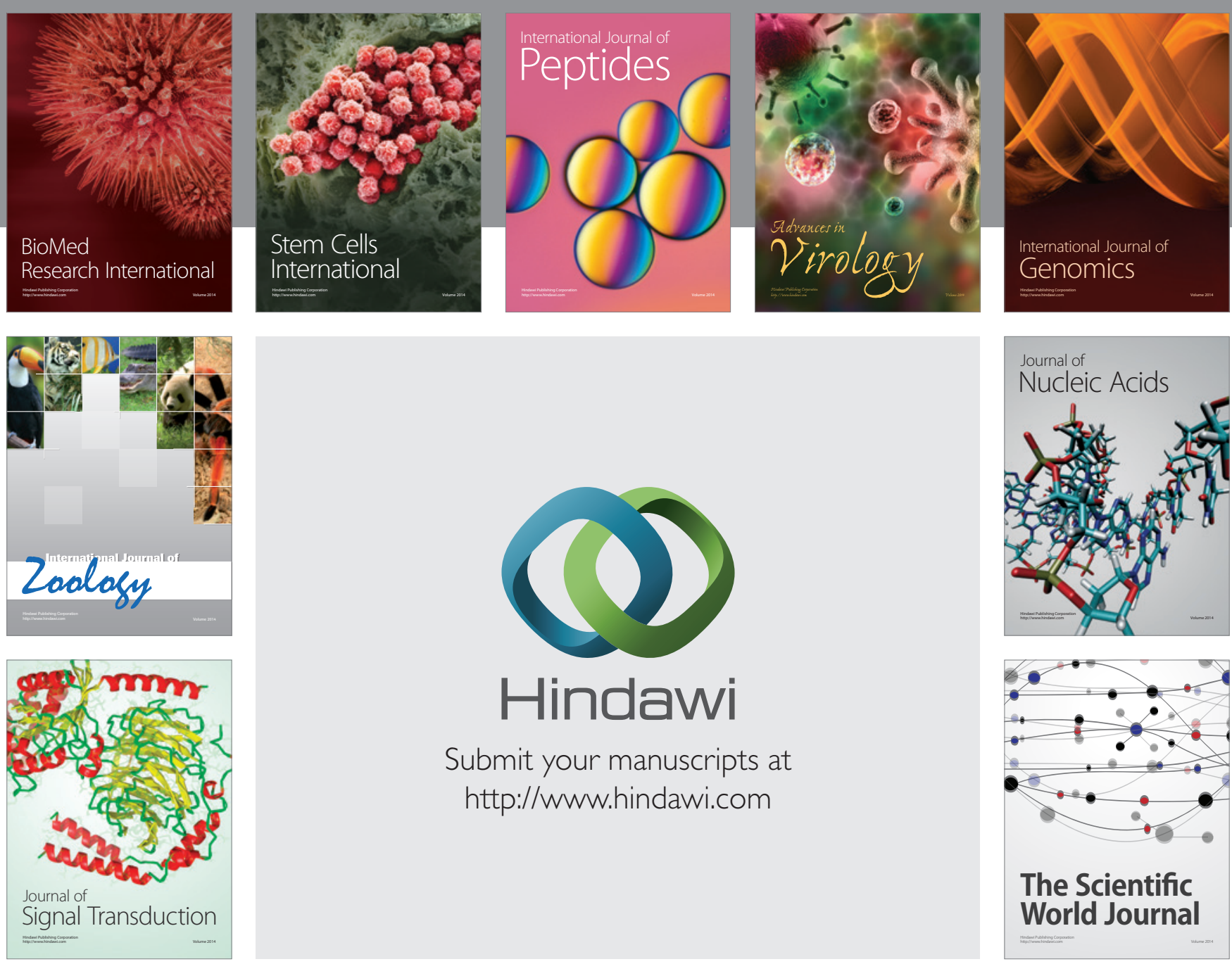

Submit your manuscripts at

http://www.hindawi.com
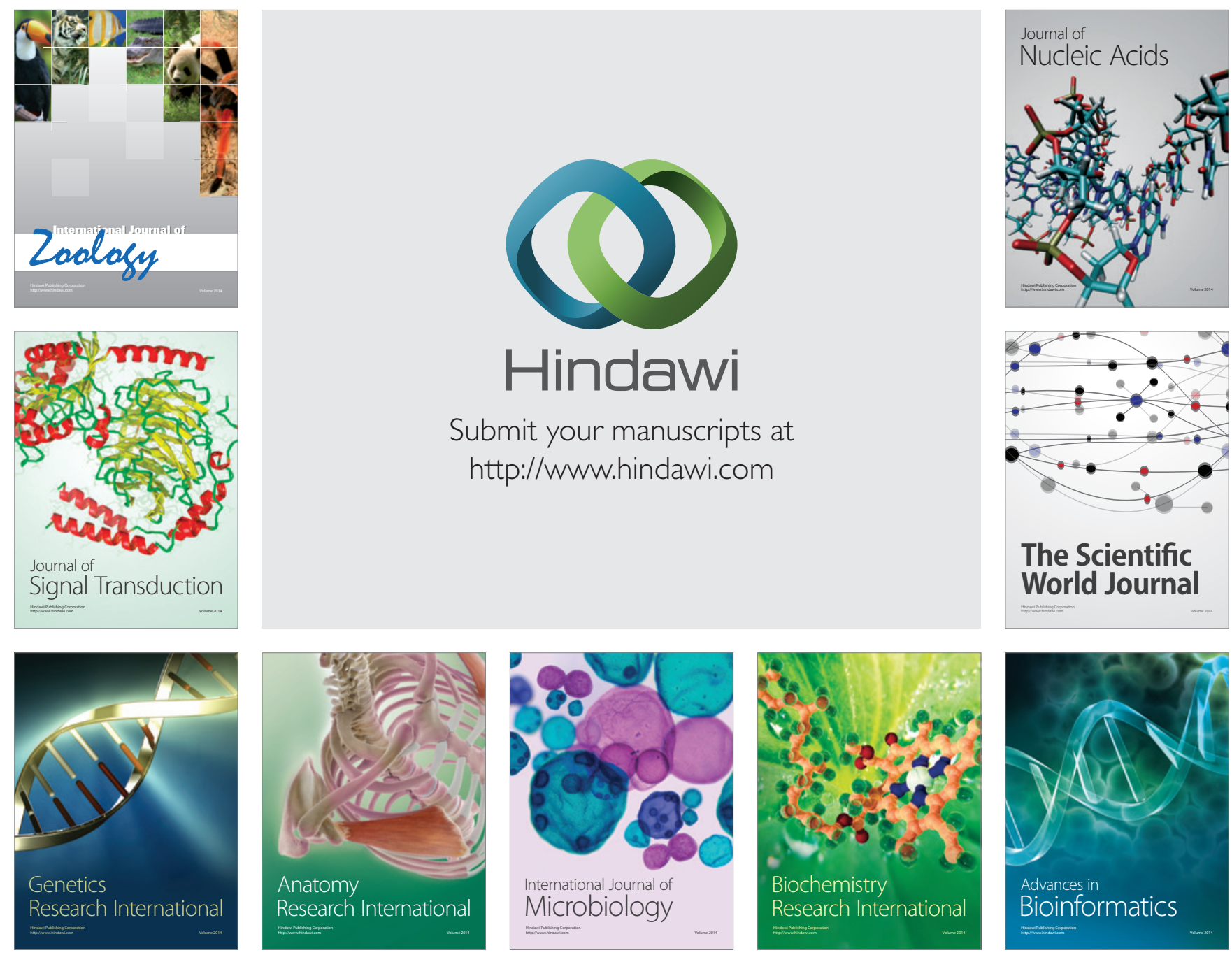

The Scientific World Journal
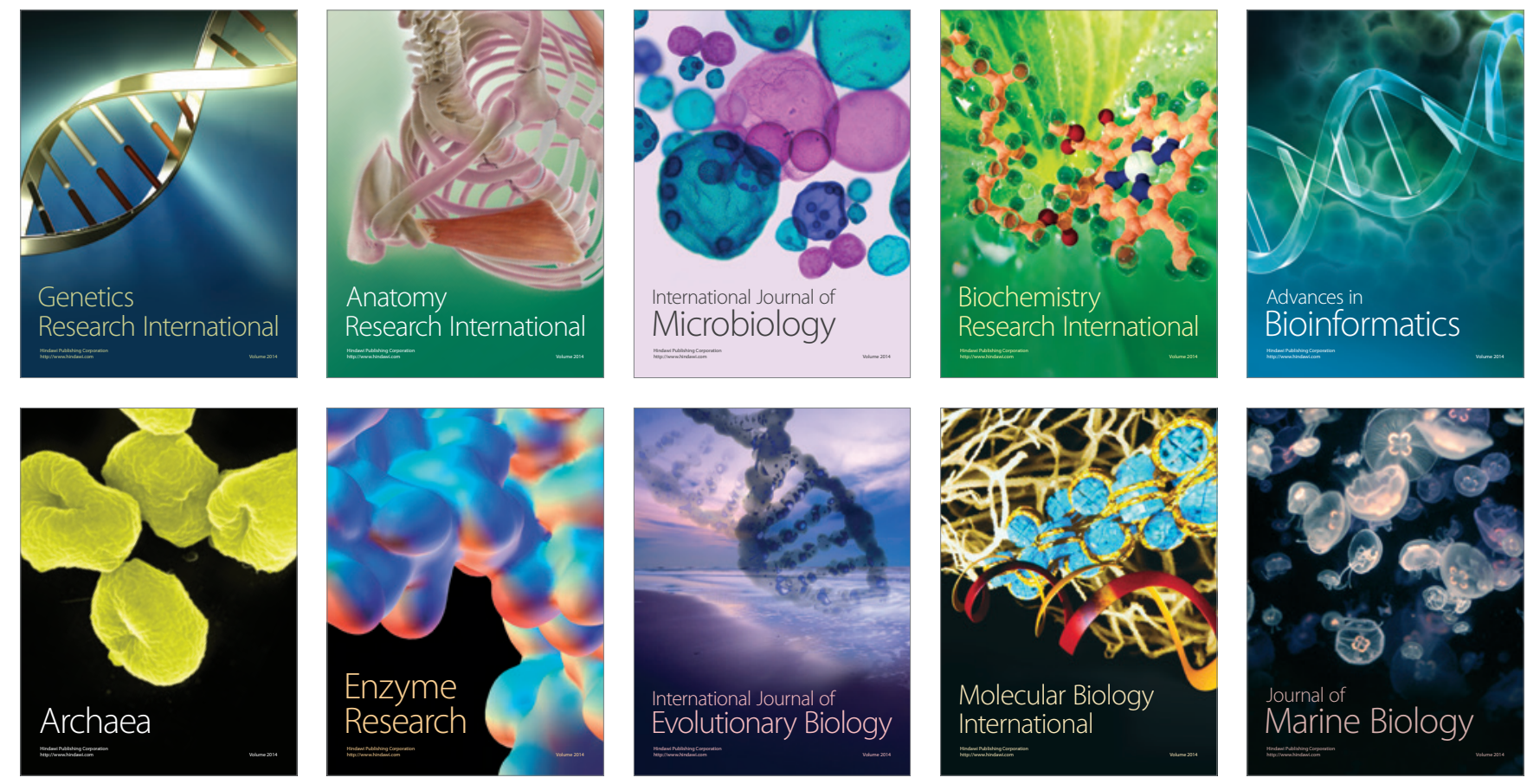